\title{
PREHISTORIA Y EVOLUCIÓN: REFLEXIONES SOBRE LA SECUENCIA ECOLÓGICO-CULTURAL HOLOCÉNICA EN EL MEDIODÍA IBÉRICO
}

\author{
PREHISTORY AND EVOLUTION. REFLECTIONS ON THE HOLOCENE \\ CULTURAL AND ECOLOGICAL SEQUENCE OF THE SOUTHERN IBERIA
}

por

\author{
DANIEL GARCÍA RIVERO ${ }^{1}$
}

RESUMEN Este trabajo expone aproximaciones teóricas evolucionistas para el análisis de espacios geográficos y sus culturas. Muestra diversos problemas metodológicos que existen en el estudio de determinados territorios, y propone, para futuras investigaciones, algunos nuevos enfoques, muchas veces mediante parámetros de estudio procedentes de distintas áreas de conocimiento. Los datos utilizados para estas aproximaciones son básicamente de carácter arqueológico, si bien obedecen a distinta naturaleza: estudios de fauna, de polen, de clima, de geomorfología, etc.

\begin{abstract}
This paper presents some evolutionist theoretical approaches to the study of human cultures, ecological environments and economic systems of the South of the Iberian Peninsula, mainly in the second part of the Holocene period. We deal with this area as a set of systems, observing the nature of the different relationships between the elements of the system, and the possible influence of external components and, in general, the evolution of the systems. Broadly speaking, we are presenting theoretical perspectives for the study of this area, some of them from other scientific fields such as Ecology. The data that we present are mainly archaeological although the majority are provided by studies of fauna, pollen, climate, geomorphology, etc.
\end{abstract}

Palabras claves

Key words
Arqueología, Biología, Ecosistema, Especie, Evolución, Individuo, Mecanismo.

Archaeology, Biology, Environment, Specie, Evolution, Individual, Mechanism.

1. Grupo de Arqueología Evolutiva de la Universidad de Sevilla (GAEUS), equipo adscrito al proyecto HUM402 del III Plan Andaluz de Investigación (Consejería de Educación y Ciencia de la Junta de Andalucía). E-mail: terratartesica@hotmail.com

ISSN: 1133-4525 ISSN-e: 2255-3924

SPAL 13 (2004): 9-34

http://dx.doi.org/10.12795/spal.2004.i13.01 


\section{CONTEXTO GEOGRÁFICO Y CRONOLÓGICO}

Este trabajo utiliza datos procedentes del mediodía ibérico, pero mayormente recoge aquellos referentes a la Prehistoria Reciente de Andalucía, y tiene vocación de centrarse en el ámbito concreto del bajo Guadalquivir. Unos 5.000 años atrás, algunas características geomorfológicas de la zona distaban bastante de las de la actualidad, encontrándose en la desembocadura del río el Golfo Tartésico citado por las fuentes escritas antiguas. Además, sabemos que en época romana se conocía este lugar con el nombre de Lago Ligustino. La paleodesembocadura bética, que daba hacia el golfo, se situaba entonces a la altura de Caura, que se identifica con la población actual de Coria del Río. Al sur de este enclave se abría una amplia llanura marítima de unos $50 \mathrm{~km}$ de este a oeste y unos 60 de norte a sur, ocupando una extensión de $1.200 \mathrm{~km}^{2}$ aproximadamente. Los estudios geológicos permiten reconstruir las características físicas de la vieja costa, que discurre en gran parte por la cota de $10 \mathrm{~m}$ de altitud. Estos trabajos han mostrado, a su vez, las características geomorfológicas de cada lugar específico; en unas zonas el litoral contaba con poca pendiente, mientras que otras contaban con perfiles abruptos. Valga, por un lado, el ejemplo de la zona media de la orilla oriental de la ensenada a la altura de Las Cabezas de San Juan, donde existía una orilla de poca pendiente y de escasa profundidad en sus aguas. Por otro lado, el caso contrario se manifiesta en la zona sureste, donde la verticalidad era más pronunciada (Schulz y otros 1992: 325). Durante la Protohistoria, el Golfo Tartésico experimentó una aceleración del proceso de colmatación; no obstante, era todavía perfectamente navegable desde el Golfo de Cádiz o Sinus Atlanticus (Arteaga, Schulz, y Roos 1995: 116).

\section{PERSPECTIVA TEÓRICA Y METODOLÓGICA}

Desde varios años hacia acá, la arqueología se afana en subscribirse al carro de la ciencia. Como en cualquier área científica, son tres las partes principales que componen el proceso de conocimiento en arqueología: 1) la técnica, 2) la epistemología y 3) la metodología. La técnica arqueológica tiene, en la actualidad, un buen recurso que solventa bastante bien la recogida de datos, conocido dentro del mundo arqueológico como el "método Harris". El cuerpo de principios que propone este autor dispone de un procedimiento acertado para una exhaustiva y exquisita recogida de documentación, al menos en lo que se refiere a los trabajos de excavación. Pero el problema radica en la confusión que ha creado el concepto de metodología. Aunque el cuerpo de conocimiento técnico de Harris se haya difundido con el apelativo de "metodología", no se refiere al tercer concepto citado. La aportación de Harris queda limitada, pues, al primer paso: la "técnica".

Las interpretaciones e hipótesis susceptibles de un conjunto de datos mantienen una conexión con la epistemología. Los postulados que propone un cuerpo teórico son exactamente los mismos sean aplicados a la arqueología, a la psicología, a la antropología, etc. El enlace de los dos primeros pasos, la técnica y la epistemología, lo cubre el tercer y último: la metodología. Lógicamente, esto se lleva a cabo mediante el diseño de hipótesis y modelos. Esta acepción de metodología es poco utilizada en el ámbito académico de la arqueología española, habiéndose señalado ya la frecuente confusión entre metodología arqueológica y técnicas de excavación y prospección (Escacena 2000a), lo que deriva en parte de que nuestro segundo paso (el de la epistemología) apenas ha hecho presencia previa.

En este punto, aún, se puede pensar que el manejo de un determinado cuerpo teórico, para el análisis de cualquier proceso relacionado con las culturas prehistóricas, no es del todo necesarioº ${ }^{2}$.

2. Existe una creencia generalizada entre algunos arqueólogos: una línea de investigación permanentemente bajo un marco teórico determinado lleva, irreversiblemente, a un dogmatismo nada práctico y productivo para con la Arqueología. 
1)

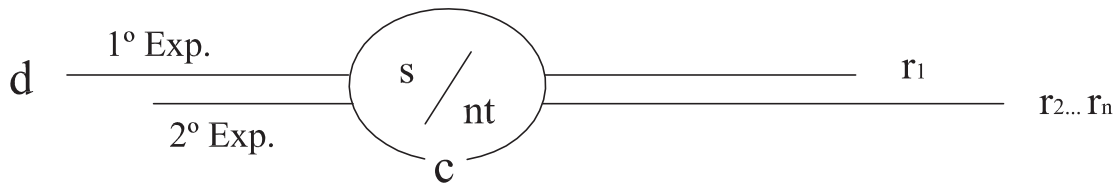

2)

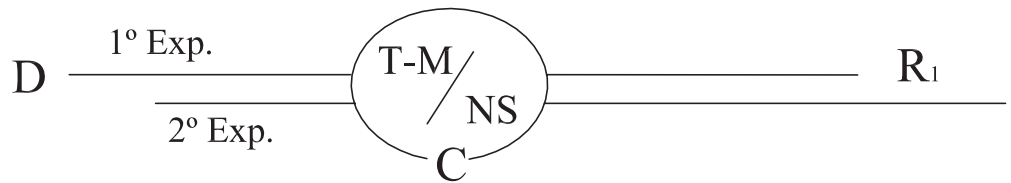

$\mathrm{R}_{1}$

Fig. 1: El caso primero ilustra la interpretación de un conjunto de datos por un científico que trabaja sin un cuerpo teórico definido. Los resultados son diferentes al cabo de varios experimentos. El caso segundo ilustra la interpretación de un conjunto de datos por un científico bajo un cuerpo teórico definido. Los resultados son idénticos al cabo de varios experimentos.

Esto puede ser correcto sólo hasta cierta medida. Muchos autores han tomado una "ideología librepensadora" para el análisis de estos procesos. En otros casos, algunos autores han seleccionado conceptos o mecanismos procedentes de diferentes cuerpos epistemológicos, elaborando un determinado "amasijo" de ideas para sus interpretaciones, en muchos casos, eso sí, bastante buenas. Aún así, estas posturas no disponen de las "ventajas" que facilitan los estudios bajo el marco teórico propio de alguna corriente de pensamiento. Y es que el análisis bajo una determinada epistemología fijada favorece la eliminación de intrusiones debidas a la subjetividad. Básicamente, y dicho de otra forma, el científico (c) que interpreta un determinado conjunto arqueológico (d) sin una corriente teórica de pensamiento fija (nt) puede verse influido por "puntos de vistas puntuales y temporales" (s) que no harán llegar siempre el experimento, en el caso de repetirlo varias veces al cabo de un tiempo determinado, al mismo resultado ( $\mathrm{r} 1, \mathrm{r} 2 \ldots \eta)$. Sin embargo, el científico (C) que interpreta un conjunto arqueológico (D) bajo una epistemología concreta (T), y por tanto con el diseño de un modelo teórico (M), no será influido por ciertos "pensamientos estocásticos" (NS) llegando siempre a la misma solución $\left(\mathrm{R}_{1}\right)$, se repita tantas veces como se quiera el experimento ${ }^{3}$ (fig. 1). En definitiva, se trata de ir elaborando pensamientos e ideas bajo unos mismos parámetros de análisis, de tal forma que se produzca un trabajo científicamente ordenado. Por último, los estudios bajo marcos teóricos concretos permiten consolidar ciertas reglas generales; para el caso de la arqueología, podemos indagar en la búsqueda de ciertos comportamientos generales, que son matizados evidentemente por particularidades culturales.

La elección de uno u otro cuerpo teórico ya queda reservada a las inquietudes científicas y filosóficas del sujeto que observa y analiza. A este respecto, existen trabajos dedicados al análisis objetivo de algunos cuerpos teóricos, mediante los que se han denominado «valores epistémicos» ${ }^{4}$.

Esto no es científicamente correcto; el uso de un cuerpo teórico como un todo -donde hagan presencia directa o indirecta todos y cada uno de sus conceptos y mecanismos- permite mayor consistencia y coherencia a la interpretación final, a menos que cualquier criterio epistemológico y/o metodológico haya perdido su autenticidad.

3. Un modelo teórico permite ser experimentado con diferentes conjuntos de datos, que poseen características básicas comunes, para medir su autenticidad; a la vez, permite ser comprobado tantas veces como se crea conveniente. En el caso de que la solución $(\mathrm{R})$ no se ajuste a la realidad, lo que debe ser rectificado y/o perfeccionado es el modelo creado bajo el marco de la metodología.

4. El filósofo de la ciencia Ernan McMullin (1983) anota cinco "valores epistémicos" como normas o modos de razonamiento del método de un científico objetivista que han sido posteriormente utilizados por otros autores; Michael Ruse (2001) realiza un estudio historiográfico y epistemológico del cuerpo teórico evolucionista. 
En este caso, nuestro trabajo recoge el cuerpo teórico del evolucionismo general y, concretamente, la teoría de la descendencia con modificación por selección natural dada a conocer por Darwin. Básicamente, esta teoría defiende que todo lo existente en la Tierra es natural y que es modelado bajo varios motores; el más importante, la selección natural. Al mismo tiempo, esta forma de pensamiento argumenta que el cambio, y en definitiva la evolución, se produce sin ninguna dirección predefinida y que, por tanto, no existe nuestra aparente noción de finalidad en los hechos. Dicho de otro modo, la naturaleza entiende de resultados, y no de intenciones. Este último punto, queda bien ilustrado en una cita de P.W. Atkins (1992: 5) refiriéndose a L. Boltzmann, al que debemos la relación entre las propiedades de la materia y el comportamiento de sus átomos:

«Muchos de sus contemporáneos dudaron de la validez de sus argumentos e hipótesis, temerosos de que su trabajo arrumbase la noción de finalidad que ellos presumían reinaba en los mecanismos profundos, del mundo del cambio, del mismo modo que Darwin la había expulsado, recientemente, de sus manifestaciones externas».

Aunque desde hace tiempo han sido introducidos algunos conceptos e ideas evolucionistas en la Arqueología, es recientemente cuando se vienen publicando, fundamentalmente desde el mundo anglosajón, obras ya de un carácter más extensivo y profundo, que tratan desde los aspectos más teóricos (Shennan 2002) e intentos de sistematizaciones para con el registro arqueológico (O’Brien y Lyman 2000) a aplicaciones de casos concretos y discusiones de diversos aspectos teóricos puntuales (Maschner 1996).

\subsection{El ecosistema como sistema ${ }^{5}$}

Como apuntamos en el primer apartado, nuestro estudio se basa en datos procedentes en su mayor parte del sur de la Península Ibérica. Aunque esta región se conoce desigualmente para los tiempos finales de la Prehistoria, algunas comarcas cuentan con estudios relativamente precisos, si bien afectan también de forma irregular a los distintos aspectos que conforman los ecosistemas (principalmente geológicos, climáticos y bióticos). A modo de ejemplo, nuestro análisis más profundo para este apartado puede centrarse en la paleodesembocadura del Guadalquivir, que durante gran parte del Holoceno estuvo unos setenta kilómetros en línea recta aguas arriba de la actual.

En parte, este territorio mantiene unas características básicas similares en toda su extensión, como son las del entorno a una zona acuática. No obstante, existen diferentes factores que han provocado una cierta diversidad de espacios. En definitiva, y de forma metafórica, diremos que todo el ámbito que abarca la paleodesembocadura del río forma un espacio donde se han ido produciendo distintas fases de una sucesión ecológica. Al mismo tiempo, la heterogeneidad de características en las distintas áreas de este espacio ha producido otras pequeñas formaciones ecológicas a un nivel más local. Básicamente, vemos dicha paleodesembocadura como un sistema formado a su vez por multitud de subsistemas. En cada uno de estos existe una gran cadena alimenticia formada por diferentes niveles tróficos, desde los elementos fotosintetizadores y productores primarios hasta las especies heterótrofas más complejas. Además de las especies animales y vegetales, existen elementos de otras dimensiones, tales como condiciones climáticas, características geológicas, etc.

Todos estos elementos influyen, unas veces de forma más trascendental que otras, en los derroteros de la sucesión ecológica del "ecosistema". En nuestro estudio, eliminamos cualquier presuposición -de carácter filosófico o religioso por ejemplo- que tenga como objetivo realzar en el

5. Para una precisión de cada uno de estos conceptos, véase Tansley (1935) y Margalef (1974). 
sistema un elemento sobre otro, ya que la razón de esta presuposición no se apoyaría en ningún criterio científico, por lo que debe ser automáticamente eliminada. Por diversas razones, el hombre ha logrado a través de su historia colocarse como el punto cenital de la creación. Esto ha influido sobremanera en los estudios científicos. Para el ojo humano, espectaculares cambios producidos en el mundo, como por ejemplo el origen de la agricultura (Childe 1992; Cohen 1993), han sido interpretados de manera desacertada, otorgando al hombre un protagonismo exagerado en detrimento de otras especies. El hombre no es, en contra de lo que generalmente pensamos, la especie elegida. Desde nuestros postulados, sólo se trata de una especie diferente y peculiar, como lo puede ser cualquier otra respecto a las demás. Así, insistimos en el uso de una metodología científica que, necesariamente, tome esto como premisa fundamental. Por tanto, cualquier elemento ha tenido o tiene la capacidad de influencia sobre otro y sobre el sistema. Así, una transformación insignificante a priori, como un cambio somático o de aptitud en el comportamiento de un individuo, puede tener unas consecuencias trascendentales en el conjunto de las poblaciones ${ }^{6}$.

El hombre no es el único elemento beneficiado en la relación que mantiene con otras especies, ya sean animales o vegetales. En multitud de casos, se producen vínculos coevolutivos donde los dos elementos directamente implicados se aportan algún beneficio. Son varios los tipos de relaciones que pueden existir entre distintas especies, pero podemos recordar ahora el caso del trigo y el beneficio que éste obtuvo a partir del neolítico por su asociación agrícola con los humanos. En este caso concreto del trigo, con antelación a su cultivo sistemático, la indehiscencia (duración del grano en la espiga) era muy escasa, ya que respondía al ciclo de reproducción que este tipo vegetal tenía para difundir sus semillas por doquier (Rindos 1990: 91). Una vez que las dos especies empezaran a mantener esta coevolución, se produjo un cambio por el cual en unas plantas el grano permaneció más tiempo en la espiga, aportando al hombre mayor probabilidad de obtener más cantidad con un número menor de plantas, lo que suponía a su vez una menor inversión de energía recolectora. Así, el hombre fomenta la reproducción de esta variedad de trigo, que se reproducirá con una difusión mayor que el resto de las variedades restantes. Esto es una clara relación coevolutiva de la que ambos sacan provecho.

De forma paralela, también otros componentes del sistema se vieron influidos por tal relación. De hecho, muchas "malas hierbas" acompañaron a los campos de cereales, con lo que aumentaron sus expectativas de reproducción y difusión.

\subsection{Breves nociones sobre mecanismos básicos}

Todos los ecosistemas desarrollan sucesiones ecológicas a causa de la entropía y de los procesos de estabilización. La segunda ley de la termodinámica sostiene que todo proceso natural va acompañado de un incremento de la entropía del Universo ${ }^{7}$. En términos generales, hay una tendencia espontánea al paso desde unos estados hasta otros en los cuales existe mayor entropía (Atkins 1992: 32-33). Aunque sea de forma metafórica, podemos relacionar la entropía con los mecanismos creadores de diversidad en cualquier formación ecológica (fig. 2). En un ecosistema dado hay una constante de mecanismos que operan en ese sentido, es decir, en la creación de desorden y desestabilización,

6. Estas cuestiones han sido tratadas por varios autores; buen ejemplo de ellas es "La hipótesis de la Reina Roja" (Van Valen 1973)

7. La termodinámica centra su estudio en un espacio dado que se denomina «sistema». El espacio próximo, que rodea a éste, se denomina «entorno». Todo ello forma un conjunto conocido como «universo». Así, dentro de lo que comúnmente llamamos universo, puede encontrarse infinidad de sistemas aislados o "universos termodinámicos" (Atkins 1992: 31-32).

ISSN: 1133-4525 ISSN-e: 2255-3924

SPAL 13 (2004)

http://dx.doi.org/10.12795/spal.2004.113.01 

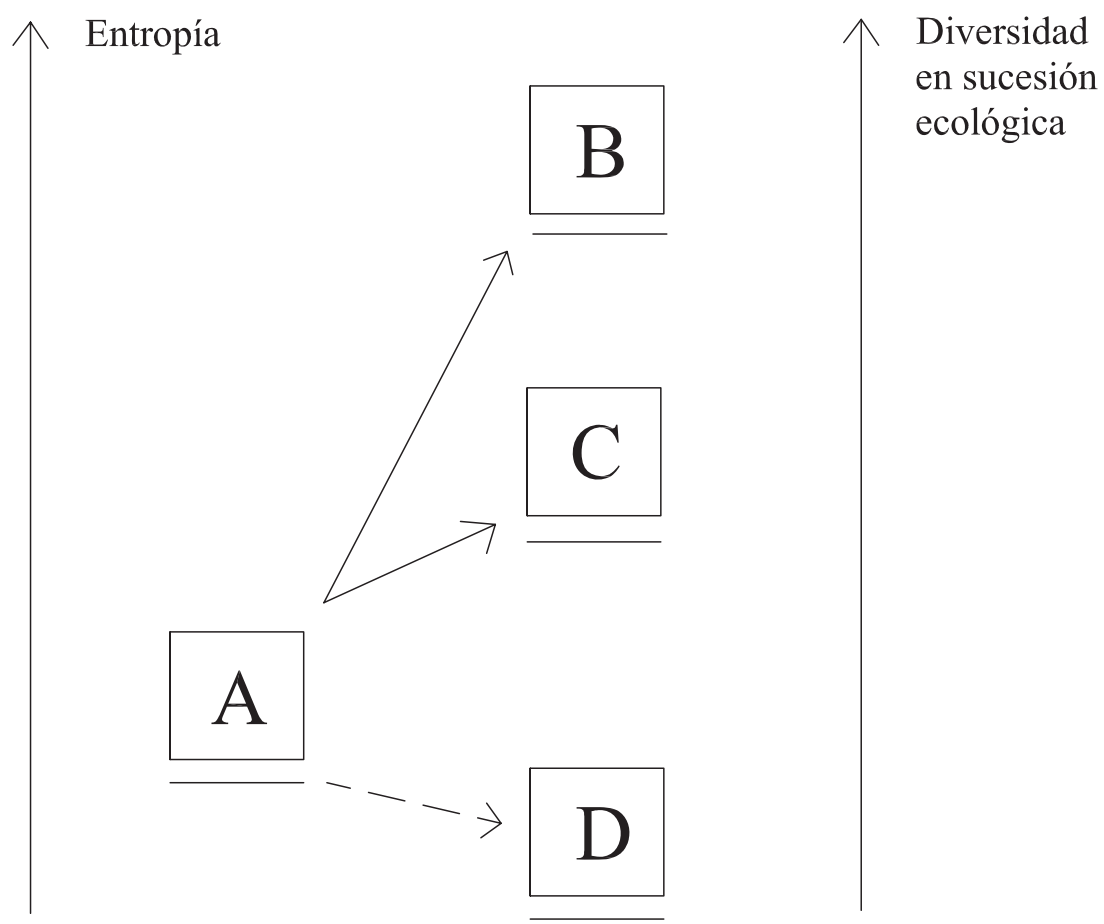

Fig. 2: Los estados A, B, C y D tienen la misma energía pero distinta entropía. Como el universo siempre dilata su entropía, existe una tendencia a producirse cambios espontáneos desde A hacia B y C, pero no desde A hacia D, ya que éste último estado posee menos entropía (Atkins 1984: 32, fig. 2.5). Nosotros añadimos la variable "Diversidad en sucesión ecológica". La tendencia a la entropía se asimila a la creación de diversidad en cualquier desarrollo ecológico. Algo similar ocurre también en otros procesos de elaboración humana como la manufactura de herramientas, de edificios, de ciudades, o en los desarrollos de los sistemas económicos y entramados sociales.

entendida como la creación de novedosas circunstancias que ensanchan el campo de la variabilidad en general ${ }^{8}$. En la tendencia opuesta, existen otros procesos de estabilización puntual y conservación. En esta otra tarea, el motor principal es la selección natural, que consigue dar una determinada dirección a todos y cada uno de los elementos que conforman un sistema mediante mecanismos de elección y preservación. Estos dos mecanismos -la variabilidad y la selección natural- ocupan un lugar central en el desarrollo de cualquier ecosistema del planeta Tierra. En primer lugar, la variabilidad viene dada por la misma reproducción. Evidentemente, hay sistemas reproductivos que permiten una mayor variabilidad que otros. La clonación produce descendientes con códigos genéticos idénticos a los de los predecesores. En este caso, la variabilidad apenas existe. En cambio, la reproducción sexual permite una variabilidad enorme ${ }^{9}$. En segundo lugar, la selección natural se encarga, mediante mecanismos de criba, descarte y preservación de caracteres dados, de encauzar las directrices de individuos

8. El concepto de «variabilidad» lo tomamos como el conjunto de opciones posibles donde opera la selección natural. Aparte, existen otros conceptos más específicos: «biodiversidad», como el número de especies en un espacio dado; «diversidad», como el reparto proporcional de individuos de cada especie.

9. Aunque la replicación genética sexual es digital, es decir, con un grado de perfección bastante preciso, normalmente la prole suele habilitar algún tipo de cambio respecto a sus progenitores. En una camada esto parece no ser importante, pero al cabo de unas cuantas generaciones es el caldo de cultivo perfecto para la creación de variabilidad. Varios estudios han achacado el éxito de las comúnmente denominadas "especies superiores" al tipo de reproducción que ostentan, la sexual. Ésta posibilita además la entrada en escena de unos mecanismos que fortalecen tales efectos, los que 
y especies. La selección natural puede actuar a distintos niveles, siendo este punto una de las luchas científicas más encarnizadas entre los mismos evolucionistas. Básicamente, puede operar a nivel de especie, de grupo, de individuo e incluso de genes. En relación con el hombre, a ello se le suma otra nueva propuesta: que la selección opera a nivel de memes ${ }^{10}$.

\section{CARACTERÍSTICAS BÁSICAS DE LOS DATOS}

Un estudio de este tipo requiere la obtención de numerosos datos procedentes de distintas áreas del conocimiento científico (Paleobiología, Climatología, Geomorfología, etc.). Una vez recogidos, los datos deben ser puestos en conexión para comprobar las hipótesis. En este punto -la conexión entre los datos procedentes de distintas áreas científicas-, nos encontramos con algunas trabas. Este apartado está destinado a mostrar este aspecto.

\subsection{Obstáculos y dificultades}

Como se ha apuntado en un principio, este trabajo recoge datos correspondientes a la Prehistoria Reciente del mediodía ibérico. Llevar a cabo un estudio de cuestiones relativas al paleoambiente de dicho territorio que intente cubrir diacrónicamente una cierta secuencia cronológica -como es la segunda mitad del Holoceno-, resulta sumamente dificultoso. Son varias las razones que sostienen este pronóstico poco alentador. Primero, los datos necesarios para la realización de un trabajo de estas características - procedentes de estudios de fauna, de polen, de clima y de geomorfología- son escasos. Aun así, esto nunca debe frenar la formulación de hipótesis al respecto (pues la ciencia se hace sobre los datos disponibles y no sobre un condicional futuro que no existe, ni se sabe cuándo llegará), que pueden ser confirmadas o rechazadas al tiempo que surjan nuevos datos. Segundo, los estudios de fauna, de vegetación, de clima y de geomorfología manejan parámetros cronológicos mucho más dilatados que los empleados en los estudios arqueológicos. Sencillamente, un análisis diacrónico de una secuencia temporal corta es prácticamente imposible. Tercero, dichos estudios procedentes de otras áreas de conocimiento no arqueológicas obedecen a una cierta disparidad de criterios metodológicos. Dicho de otra forma, no hay un consenso entre los estudiosos del tema sobre cuáles son las variables del registro más fiables -como la cantidad de los restos óseos documentados, la estimación de kilogramos de carne producida por tales restos óseos, etc.- en las que basar sus interpretaciones ${ }^{11}$.

engloba la selección sexual. En definitiva, este sistema reproductivo permite generalmente una mayor rapidez en el ritmo de cambio de las especies y una mayor difusión en número de individuos.

10. Este concepto fue acunado por R. Dawkins (1976), y ha sido desglosado posteriormente por otros autores. Básicamente, un meme es la unidad mínima de replicación cultural. Esta línea de investigación -la memética- defiende que el meme es similar al gen, en cuanto que es un replicante (reúne las tres condiciones básicas: herencia, variación y selección), pero que difiere enormemente de aquél por sus mecanismos de replicación; el más eficaz en la memética, la imitación (Blackmore 2000).

11. Esta heterogeneidad a la hora de seleccionar las variables más propicias es fácilmente entendible, pues estos estudios afloran desde líneas de investigación bastante recientes; en estos primeros pasos del conocimiento, es difícil concluir de manera fiable cuáles son los criterios más acertados, máxime cuando existe el riesgo de una gran tendencia a la creación de axiomas. Desde aquí, agradecemos el esfuerzo que estos pioneros están llevando a cabo, pues su fruto será muy apetitoso para la Arqueología.

ISSN: 1133-4525 ISSN-e: 2255-3924

SPAL 13 (2004)

http://dx.doi.org/10.12795/spal.2004.i13.01 
En definitiva, los trabajos sobre cuestiones medioambientales de la Prehistoria tienen aún poca capacidad y rigor. A modo de sugerencia, el estudio no debe tratar una secuencia temporal excesivamente corta, y el marco geográfico debe englobar una extensión relativamente amplia. Por tanto, los objetivos de este trabajo se limitan a: exposición de datos disponibles, muestra de problemas metodológicos y posibles soluciones, propuesta de enfoque teórico, despliegue de conceptos, leyes y mecanismos influyentes; apunte de parámetros de análisis procedentes de otras áreas científicas, análisis de los elementos más viables del sistema -en relación a los datos disponibles- y, por último, ofrecer algunas ideas que faciliten el enfoque de análisis en estudios venideros más concretos, meramente metodológicos.

\subsection{Propuesta de perspectiva de análisis y aplicaciones en el registro vegetal}

El registro faunístico y polínico muestra - una vez se han abordado ya aspectos como, por ejemplo, la diferencia entre edades y sexos- que en los restos de determinadas especies existe una gran heterogeneidad morfológica. Por norma general, la diferencia entre los esqueletos de individuos (y entre los órganos perdurables de los vegetales, potencialmente recuperables) de la misma especie no es muy acusada ${ }^{12}$. De esta forma, la diversidad morfológica acusada en una especie del registro responde a la existencia de subespecies.

Es cierto que, en muchos casos, las alteraciones posteriores - procesos postdeposicionales y accidentales- pueden enturbiar la "imagen" del registro. Sin embargo, la frecuencia con la que se documenta este hecho - la citada diversidad morfológica- obliga a indagar en esta cuestión, esto es, a buscar unos mecanismos que faciliten una explicación -y a ser posible una predicción- que satisfaga aquellos casos.

Es bien conocido que las especies más difundidas y comunes en un determinado espacio son las que más tienden a variar (Darwin 1999: 107). Esto tiene lógica explicación. Primero, que estas especies, al estar representadas por un mayor número de individuos, tienen una reproducción alta; en términos generales, dejan más descendencia que las restantes. Al producirse mayor descendencia se produce directamente mayor variabilidad. Y segundo, las especies mayoritarias suelen ocupar áreas geográficas más extensas; así, se relacionan con un mayor número de organismos diferentes. Las circunstancias novedosas que estas especies afrontan fomentan la preservación de cambios somáticos y de comportamiento, pues en el transcurso de cada generación los individuos heredan las pequeñas ventajas que a sus progenitores les permitieron adaptarse o ser más eficientes en esos contextos nuevos. También aquí, en definitiva, se produce mayor variabilidad.

Estas ideas empujan a buscar explicaciones acerca de las interesantes cuestiones que encierran los yacimientos. Con la debida cautela -porque, entre otros factores, es imposible que el registro paleontológico conserve todas las especies y todos los individuos que han existido- debemos formular una hipótesis para estas cuestiones. Y ésta es que las especies que cuenten con un mayor número de subespecies fueron más comunes y estuvieron más difundidas que las restantes. Dicho de otra forma, las especies que más variabilidad morfológica somática muestran -es más difícil

12. La diferenciación entre especies está basada, en gran parte, en esta cuestión morfológica del esqueleto; las clasificaciones paleontológicas e, incluso, otras de especies aún vivientes se apoyan en este criterio. Por otro lado, recogemos una frase que refuerza la idea de la homogeneidad morfológica del esqueleto de una especie: "Como las especies de un mismo género suelen tener -aunque de ningún modo invariablemente- mucha semejanza en costumbres y constitución, y siempre en estructura...» (Darwin 1999: 130). Por tanto, si lo son entre las especies de un género, lógicamente, lo son también entre los individuos de una misma especie. 
recuperar la variabilidad conductual en el registro arqueológico- serían más abundantes y estarían más difundidas que las que poseen menos heterogeneidad. Como en gran parte de los casos es complicada la diferenciación de grupos entre una misma especie, esta idea puede hacerse extensible -y quizá más útil- a otros niveles de análisis, como por ejemplo el caso de las especies que conforman un determinado género.

Resulta interesante llevar estas predicciones teóricas al campo de la práctica, o sea, a los datos del registro. Considerando los análisis de polen de yacimientos correspondientes a la zona del presente estudio, nuestra predicción parece correcta. Son mayormente la encina y el pino los que disponen de un mayor número de variedades. Coincidiendo con nuestra predicción, son los tipos más difundidos cronológica y geográficamente, y, además, en número de individuos, a lo largo del Holoceno; tienen buena capacidad de adaptación a una cierta diversidad de ambientes.

En general, el grupo de Quercus está bien documentado en el sur de la Península Ibérica. Son muchos los taxones que lo conforman, como el roble albar (Quercetalia robori-petraeae), el quejigo o roble carrasqueño (Quercetalia faginea), el alcornoque (Quercetalia suber) y la encina (Quercetalia ilex). Los tres primeros han sido documentados en Sierra Morena y en las estribaciones occidentales de la Subbética, así como en parte de los rebordes del golfo tartésico. El cuarto y último taxón, se documenta mayormente en la zona de campiña (Díaz del Olmo 1989: 16). Al norte de la gran paleoensenada bética, algunos kilómetros río arriba, en el yacimiento cordobés de Ategua, han sido documentadas varias especies pertenecientes al grupo de Quercus. Este emplazamiento tiene una continuidad cronológica desde la Edad del Bronce hasta fechas romanas, y sus restos polínicos muestran la presencia de Quercus t. ilex. (López 1986). Al oeste, en la turbera de Huelva, datada en los comienzos del Subboreal, las especies de este grupo parecen predominar respecto a otras en el registro (López 1978). Estudios antracológicos realizados en el yacimiento de Cerro Juré muestran el predominio de Quercus ilex-coccifera entre las especies arbóreas ${ }^{13}$ (Nocete y otros 1998: 100). Además, el grupo de Quercus ha sido bien documentado también en la parte oriental de Andalucía. En la turbera de Padul, al Sur de Granada, la capa de sedimentación que nos interesa mayormente es la superficial, que data del 3030 a.C. Aquí, la proporción de encinar mixto sobrepasa el 50\% en el diagrama polínico (López 1978: 20). Asimismo, en el yacimiento de la Cueva del Nacimiento (Pontones, Jaén) aparecen especies de este grupo vegetal en las dos fases que forman el sitio arqueológico (López 1986: 156). En fin, en las turberas meridionales Quercus es el grupo dominante desde la mitad del Holoceno, a excepción de la zona costera, donde destacan el arce y el pino hasta el período Subatlántico.

Respecto al territorio que hoy ocupa Extremadura, también el grupo de Quercus parece haber sido bastante común. Especies pertenecientes a este grupo han sido documentadas en varios yacimientos arqueológicos. Son los casos de Cerro del Castillo de Alange (Badajoz), Cerro de la MuelaAlcazaba de Badajoz, y otros, en donde estas especies muestran un elevado índice en las columnas polínicas, como son los casos del poblado de la Sierra de Aljibe (Aliseda, Cáceres), el complejo arquitectónico de La Mata (Campanario, Badajoz) y el oppidum de Hornachuelos (Ribera del Fresno, Badajoz) (Grau, Pérez y Hernández 1998).

Como apuntamos anteriormente, junto al encinar, el pinar es el grupo más difundido. En la turbera de Huelva han sido documentadas especies como el pino piñonero -Pinus pinea- y el pino resinero -Pinus maritima-, las cuales lideran cuantitativamente de forma clara el registro vegetal de este yacimiento para el comienzo del Subboreal (López 1978: 20). Igualmente, la gran difusión de este grupo queda demostrada por su documentación en el oriente andaluz. Tenemos evidencias

13. En este caso hay que anotar que estos estudios se realizaron con muestras procedentes de hornos metalúrgicos, con lo que las especies representadas se limitan posiblemente a aquellas de mayor potencial calorífico.

ISSN: 1133-4525 ISSN-e: 2255-3924

SPAL 13 (2004)

http://dx.doi.org/10.12795/spal.2004.i13.01 
en los yacimientos de Ategua y Cueva del Nacimiento (en la primera fase de este yacimiento se documenta un aumento de este grupo arbóreo fechado en el periodo Atlántico); además, se suma el yacimiento de Los Castellones (Céal, Jaén) (López 1986: 156). También se registran en otros puntos, como Almizaraque, en la provincia de Almería, donde están presentes en las dos fases de este emplazamiento, aunque son más abundantes en la primera etapa y señalan un descenso posteriormente (López 1986: 156). En la turbera de Padul, los altos valores de Quercus están seguidos de Pinus (López 1978: 20).

Según los datos obtenidos desde estos enclaves, Quercus y Pinus son los grupos más numerosos, sin lugar a dudas, en las zonas montañosas del área meridional peninsular. Por lo que hemos visto, dominan el paisaje del entorno de Golfo Tartésico, y predominan más a medida que nos trasladamos a las zonas altas de Sierra Morena y de la Subbética. Lógicamente, la inexistencia de estos grupos en la parte central del Bajo Guadalquivir se entiende por la ubicación del antiguo golfo. Además, la naturaleza del suelo en esta zona concreta no es muy propicia para el éxito de estas especies. En la zona del valle del Guadalquivir, la composición de suelos margosos-yesíferos es poco adecuada para la vegetación arbórea de Cupulíferas y Abietáceas, donde se encuentran la encina y el alcornoque, y el pino, respectivamente (López 1978: 13).

De forma general, podemos establecer una secuencia diacrónica de estos tipos. En la fase Atlántica los pinares secundan a los encinares; esto se mantiene en el Subboreal, aunque los pinos reflejan un pequeño descenso a causa de la disminución de la humedad. Posteriormente, durante el Subatlántico son de nuevo estos dos grupos los que sobresalen ante el resto de las especies arbóreas. Esto se confirma también en un estudio realizado en gran parte del área onubense, donde todavía en la actualidad estos grupos perduran como los más comunes (Horowitz 1981).

\section{LOS AGENTES AMBIENTALES Y SUS INFLUENCIAS}

Los agentes ambientales influyen sobre cualquier formación ecológica, a muchos de sus niveles. La misma estructura material de un ecosistema, como nivel general, está moldeada baja estos agentes. Al mismo tiempo, los grupos e individuos animales o vegetales mantienen una relación directa con estos aspectos. También al nivel de microorganismos, como por ejemplo los que se pueden hallar en una formación acuática bentónica, estos agentes climáticos desempeñan incluso una mayor importancia, pues pueden determinar en mayor grado a unos individuos de ciclo de vida corto. Un enfriamiento general, un aumento de la pluviosidad, etc., son causas de grandes cambios. Los agentes climáticos en general actúan directamente en la existencia cuantitativa de recursos. Este aspecto influye en la sucesión de unas u otras especies en cualquier espacio geográfico. Sabemos, desde la Ecología, que cuestiones como la temperatura, la luz solar, la pluviosidad, los ciclos lunares y de día-noche, etc. son esenciales para el entendimiento de la sucesión de la vida y de sus "ritmos" y "regularidades" (Margalef 1974).

Desde la Ecología, en el estudio del desarrollo de un ecosistema, la componente puramente ambiental -o la acción del medio sobre los organismos- se denomina «alóctona» ${ }^{14}$. Por otro lado,

14. Por citar algún ejemplo, aunque a escalas geográfica y cronológica que superan las de nuestro estudio, valga el análisis de Cerling y otros (1997; citado en Arsuaga y Martínez 2000: 72). Con base en el análisis de la cantidad de isótopo del Carbono 13 procedente de diversos animales herbívoros, se constató que alrededor de hace unos 8-6 millones de años se produjo una explosión importante de las plantas de ecosistemas abiertos (de tipo C4) en detrimento de las masas forestales (de tipo C3), lo que se interpretó como causa de un notable descenso de la concentración de dióxido de carbono en la atmósfera. (Acerca de las fotosíntesis y de otras diferencias entre las plantas de tipos C3 y C4, véase Smil 2001: 97 y ss). 
la componte «autóctona» se refiere a los cambios ocasionados por organismos del ecosistema ${ }^{15}$ (Margalef 1974: 738). Esta última es igualmente interesante y, en muchos casos, determina los derroteros de la formación ecológica sobre el aspecto ambiental. La relación entre los distintos organismos de un territorio tiene gran importancia en cuanto al desarrollo de unas u otras especies. La lucha por la existencia provoca que las especies hagan cada vez más complejos sus organismos $\mathrm{y}$, por tanto, el sistema en general.

El trabajo de precisar, en el análisis de cualquier cambio dado, entre causas «alóctonas»y «autóctonas» no prescinde de dificultades. A escala planetaria, se sabe que, a partir de principios del periodo Atlántico -5.000 a.C.-, las especies arbóreas reducen proporcionalmente su número respecto de las herbáceas y arbustos. La razón alóctona defendería un resecamiento climático ${ }^{16}$, mientras que la vertiente autóctona argumentaría que es la práctica de la agricultura humana la que provoca tal circunstancia. En esta última línea, se encuentra la idea apuntada sobre la intensa degradación del paisaje arbóreo de Extremadura a partir de la Edad del Bronce que, con base en yacimientos anteriormente señalados como el Cerro del Castillo de Alange (Badajoz), el Cerro de la Muela-Alcazaba de Badajoz, el poblado de la Sierra de Aljibe (Aliseda, Cáceres), el complejo arquitectónico de La Mata (Campanario, Badajoz) y el oppidum de Hornachuelos (Ribera del Fresno, Badajoz), se interpreta como causa al incremento de la carga herbívora y a las prácticas agrícolas que el hombre impone sobre el territorio. Fortalece esta idea la existencia en estos yacimientos de ciertos taxones vegetales que suelen asociarse a las áreas de cultivos y pastizales tales como Convolvulaceae, Lamiaceae, Brassicaceae, Poaceae, Asteraceae, Plantaginaceae, Chenopodiaceae, Caryophyllaceae, etc. (Grau, Pérez y Hernández 1998).

Es prácticamente imposible tratar esta cuestión en circunscripciones relativamente pequeñas, como sería la paleodesembocadura del Guadalquivir. En este caso concreto, los yacimientos que poseen datos correspondientes a dicha materia se encuentran en zonas relativamente distantes de la zona. P. López concluye que durante la fase Atlántica, en las zonas montañosas de Andalucía, Quercus y Pinus representan los valores más altos, y que las herbáceas llegan a alcanzar unos índices del 50\% del registro, lo que permite hablar de bosque abierto. Sin embargo, apunta que en las zonas costeras, para el mismo periodo, las herbáceas alcanzan el 80\% del registro (López 1978: 40). De frágil manera podemos apoyar el ascenso de las herbáceas alrededor de la mitad del Holoceno. Aunque es difícil dilucidar con gran precisión el porqué de tal proceso, tenemos interesantes noticias sobre un yacimiento situado en el Guadalquivir medio: Ategua (Córdoba). Este asentamiento se desarrolla desde la Edad del Bronce hasta tiempos romanos. En toda su secuencia, los índices de herbáceas rebasan el 80\%. Desde esta columna polínica, se ha interpretado que el sitio sufrió una gran deforestación arbórea a causa de las intensas actividades agrícolas. Fortalece esta idea también el haber sido documentada la existencia de Asphodellus -en el tercio superior del diagrama-, que denota la gran degradación producida en el suelo (López 1986: 156).

No obstante, en muchas otras ocasiones los datos apoyan la otra vertiente, con lo que podemos resumir que ambas componentes -alóctona y autóctona- participan en el proceso gradual por el cual los árboles van cediendo paso a otras especies menos leñosas. Hemos hecho referencia a este ejemplo sólo para reflejar la dicotomía existente acerca de la influencia posible de los agentes ambientales sobre cualquier población; el tratamiento de esta cuestión concreta excede los límites de este trabajo.

15. Al mismo tiempo, la Biología en general los denomina «factor abiótico» $\mathrm{y}$ «factor biótico», respectivamente (Martín, Ruse y Holmes 1996).

16. En términos generales, los agentes que pueden actuar como factores de cambios climáticos han sido clasificados en cinco categorías: sucesos catastróficos, evolución geodinámica del planeta, comportamiento del sistema hidrosfera-atmósfera, fluctuaciones naturales de la órbita solar de la Tierra y, por último, efecto de la biosfera (Arsuaga y Martínez 2000: 64).

ISSN: 1133-4525 ISSN-e: 2255-3924 


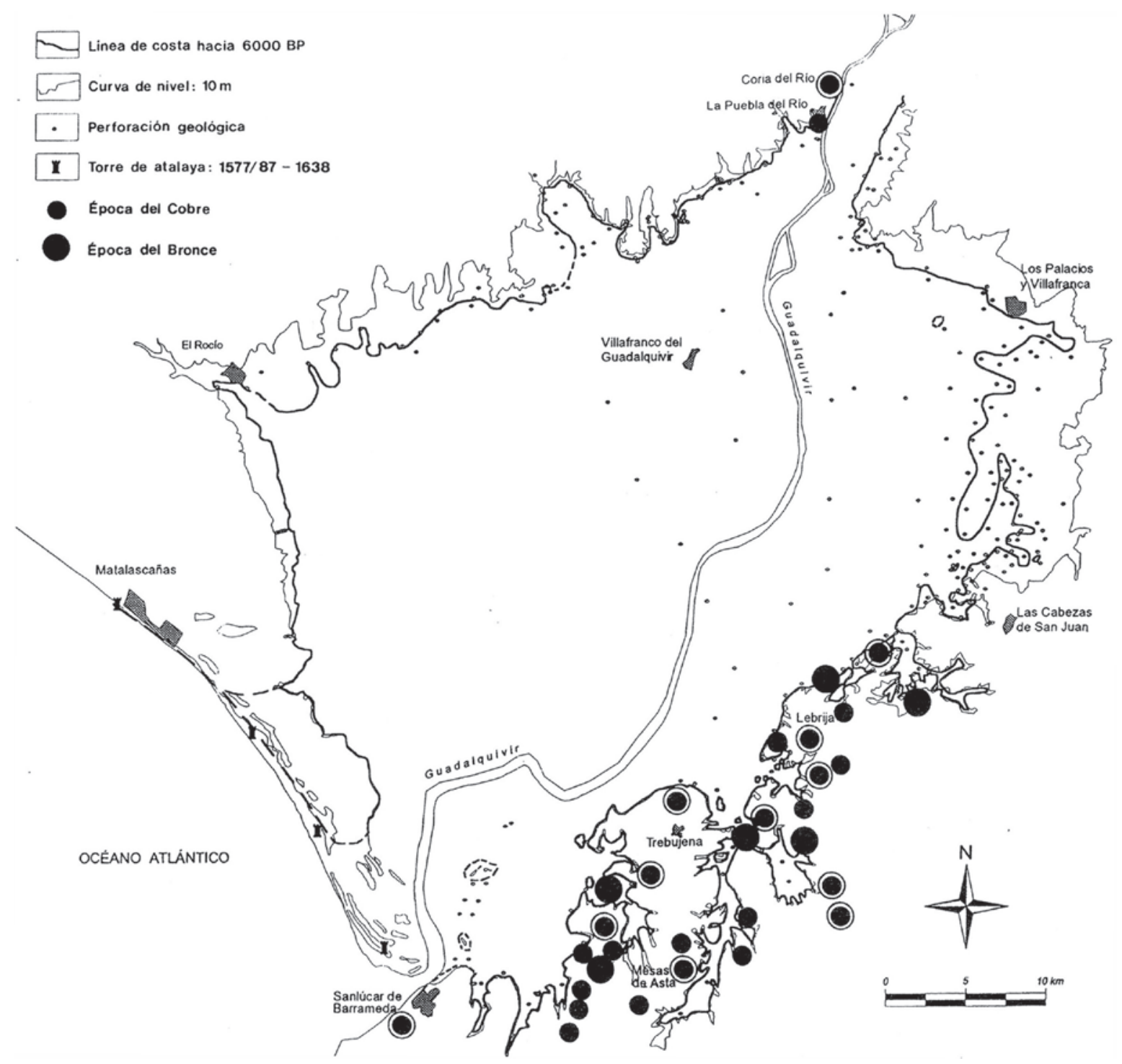

Fig. 3: Distribución de los principales yacimientos arqueológicos en las épocas del Calcolítico y del Bronce, según (Arteaga y Roos 1992: fig. 3).

Lo que hemos denominado bajo el apelativo de agentes ambientales, engloba, además del clima, otros aspectos. Agentes ambientales son todas las características climáticas y físicas del medio circundante; no son el determinante para la elección y, posteriormente, el asentamiento de un poblado prehistórico, pero son aspectos de suma importancia. Básicamente, a medida que una población crece se extiende sobre espacios geográficos que permiten menos facilidad en la obtención de recursos. A lo largo de su historia, el animal humano ha ido creciendo y difundiéndose por unos u otros entornos. Generalmente, el hombre prehistórico ha seleccionado el mejor espacio geográfico donde ubicar su paradero, al menos, siempre que ha tenido la posibilidad de hacerlo.

La influencia de las condiciones físicas y climáticas del medio se advierte fácilmente al observar la distribución de los yacimientos prehistóricos documentados en la zona del Bajo Guadalquivir (fig. 3). Aquí, se refleja una inmensa mayoría de asentamientos ubicados en la margen oriental de 
la bahía. Podría deberse al efecto causado por el régimen de pluviosidad que, de alguna manera, tendría comportamientos diferentes a uno y otro lado del golfo debido a la relación dual entre hidrosfera y atmósfera. Pero esto es sólo una reflexión en alto no corroborada por las medidas pluviométricas actuales. Lo que no ofrece dudas es la distinta naturaleza geológica que tienen los suelos a uno y otro lado de la ensenada. En la parte occidental, dominan los suelos de arenas, calcarenitas y conglomeraciones de arcilla. Al este del golfo, lo hacen los suelos de moronita, arcillas yesíferas, distostroma subbético y más escasamente calizas, arcillas y margas (Bejarano 1997: 2527). Estos últimos, correspondientes hoy a la margen izquierda del Guadalquivir, son mucho más aptos para el cultivo de multitud de especies vegetales. Por lo tanto, resulta lógico que la mayoría de poblaciones humanas de la prehistoria reciente se asentasen en esta parte de la desembocadura para, mediante técnicas agrícolas, sacar rendimiento energético.

\section{LAS RELACIONES ENTRE LOS ELEMENTOS DEL SISTEMA}

Hasta la actualidad, la ciencia, concretamente la Biología, sólo ha demostrado un criterio para comparar el éxito entre las especies: el éxito reproductivo y, a la sazón, la perpetuación del tipo. Cualquier otro criterio que se estime como el factor clave para dicha comparación no parece, por tanto, científicamente correcto. Normalmente, las ciencias humanas y sociales han trabajado con otras variables para indagar en estos aspectos. Tal como su nombre refleja, las ciencias sociales han primado en sus estudios variables de sociabilidad; valoran unos grupos sobre otros normalmente porque profesan unos lazos sociales más complejos. De igual manera, podemos apuntar cómo las ciencias humanistas han estimado sobremanera algunos aspectos, tales como la tecnología empleada, la filosofía y la religión ${ }^{17}$. Pero todo ello, se basa en una visión antropocéntrica de la vida y, por consiguiente, no respeta una manera científica de pensamiento. Un estudio que se proponga indagar en el mundo de las relaciones entre distintas especies -intereses, dificultades, competiciones, pactos, fracasos, muertes, éxitos, prosperidades, etc.- debe de trabajar sobre unas reglas fundamentadas y experimentadas científicamente; para ello, ya hemos señalado el único criterio que por momento la ciencia ha demostrado: el éxito reproductivo.

Debemos, por tanto, aceptar la idea de que cualquier estrategia somática o de comportamiento vigente en un ser vivo, puede haber estado anteriormente relacionada de forma directa con su posibilidad de reproducción y, por ende, con su perpetuación en la Tierra. Hasta este punto, todo resulta sencillo y pacífico. El problema reside en un punto: la disponibilidad de recursos. Una vez las especies tienen que competir entre ellas para conseguir captar los recursos necesarios que le faciliten reproducirse, surgen las dificultades. Entonces, nacen otras nuevas modalidades de relación, que van desde la competición entre dos individuos hasta la coalición de varios tipos de especie que se benefician entre si $^{18}$.

17. Conviene precisar que no se trata tampoco de subestimar la influencia de éstas últimas en el desarrollo humano en general, sino más bien de evitar que se sobrevaloren de forma sistemática. Incluso, no hay lugar para una división antagónica y tajante entre estas posturas. Todas ellas pasan a formar parte de complejos sistemas -que quizá deban ser analizados individualmente y de forma detallada-, donde unas y otras se encuentran entrelazadas y, frecuentemente, conformando mecanismos de retroalimentación que empujan la evolución en un sentido u otro.

18. Esta cuestión ha sido bien estudiada en diferentes áreas del conocimiento. La Biología en general ha tratado estos temas con gran profundidad desde hace años. Sin embargo, el análisis de estas cuestiones en otros campos del conocimiento es mucho más reciente. Wilson investigó profundamente acerca de las relaciones en animales sociales, como insectos y hormigas. Posteriormente, entre otras áreas, la Psicología y Arqueología están trabajando en estas perspectivas;

ISSN: 1133-4525 ISSN-e: 2255-3924

SPAL 13 (2004)

http://dx.doi.org/10.12795/spal.2004.113.01 
La existencia de distintas especies, así como las diferentes relaciones que éstas mantienen entre sí en un espacio dado (cosa que trataremos en las líneas siguientes), marcan en gran parte el desarrollo del sistema ecológico. De manera básica, introduciremos algunos conceptos y reglas que muestran algunas regularidades de la sucesión de la vida en cualquier formación ecológica.

\subsection{Nociones desde la teoría}

Cuando los recursos escasean, las relaciones entre grupos o individuos tienden a desarrollarse de forma más violenta. Generalmente, la falta de alimento hace operar a cualquier individuo a una búsqueda de recursos, ahora más peligrosa. En estas circunstancias, los intereses genéticos y culturales crean una tendencia natural: el disfrute propio de los beneficios y, en segundo término, aportar algunas de las mercedes a los más próximos genética o culturalmente.

Los recursos disponibles son limitados normalmente. Sin embargo, el número de individuos que nace siempre suele ser mayor al que un nicho ecológico determinado puede soportar. Se produce, pues, una criba que se lleva a cabo mediante un filtro selectivo que permite sobrevivir a los más aventajados, o a los que más rápidamente cambien sus estrategias para con las nuevas circunstancias. De esta forma, el ritmo de cambio de evolución de una especie se alza como un valor significativo; de ello, dependerá la pervivencia de la especie ${ }^{19}$. El ritmo de cambio de una especie es, hasta cierto punto, una variable que admite ser medida. Existe una regla conocida como Principio de Fisher o Teorema Fundamental de la Selección Natural, que argumenta que el ritmo con que una población aumenta su adecuación al ambiente en un momento dado es igual a la variación genética con la que cuenta dicha población (Ayala 1994: 67). De esta manera, observamos que las especies más aptas son las que cuentan con una mayor variabilidad. Por otro lado, ya vimos, en el apartado 3.2., que generalmente las especies que cuentan con mayor variación son las más difundidas. Así, vemos como diferentes mecanismos operan en el mismo sentido, estableciendo unos dispositivos de retroalimentación, que empujan las directrices de una formación ecológica por unos rumbos dictaminados por la selección natural.

En el desarrollo de cualquier ecosistema, las diferentes especies se relacionan de distintas formas, que se van modificando, generalmente, a un ritmo suave. Existen, básicamente, dos tipos de relaciones entre especies o individuos (las cuales engloban otros subtipos). El primero, el mutualismo; el segundo, la competición. El mutualismo existe cuando dos especies distintas se coaligan de tal forma que ambas reciben beneficio, sin la inversión de un aporte añadido de energía. De esta manera, el producto que ambas especies recogen les permite un mayor índice de supervivencia, lo que posibilita elevar su biomasa. Aunque nosotros englobaremos las relaciones de "buena convivencia" bajo el término «mutualismo» (indistintamente, también se utiliza el concepto "simbiosis»), existen varios subtipos. La relación entre dos o más individuos de una misma especie se denomina "cooperación intraespecífica»; entre individuos de especies distintas, "cooperación interespecífica». Se usa el término «comensalismo», cuando sólo una de las dos partes de la relación se beneficia; la otra, en cambio, no es afectada (Martín, Ruse y Holmes 1996). Por otro lado,

\footnotetext{
la Teoría de Juegos está centrando gran parte de su trabajo en cuestiones de sociabilidad en grupos dados. Al respecto, véase (Cox, Sluckin y Steele 1999; Sigmund, Fehr y Nowak 2002).

19. A este respecto, la Biología ha diferenciado entre especies "oportunistas" y especies "especializadas". Las primeras se mantienen de recursos menos elaborados, que no requieren una especialización alta para la obtención de su beneficio. Las segundas mantienen una conducta mucho más uniforme y constante; generalmente, son menos prolíficas que las primeras, pero resisten más; aunque, un cambio extremo en las circunstancias, puede llegar a ser más letal para las especializadas.
} 
una relación competitiva entre dos especies dadas -o entre diferentes grupos de una especie- se produce cuando la obtención de energía de una de ellas es incompatible o perjudica a la otra. Dentro del grupo genérico que denominamos relaciones competitivas, existe un tipo que podríamos denominar "relación competitiva de coevolución positiva mutua". Básicamente, es un trato de competición pero que al mismo tiempo permite algún tipo de beneficio hacia ambas. De todas estas relaciones depende, en gran parte, la sucesión ecológica de un nicho ambiental.

A nivel general, el mutualismo queda bien ejemplificado en la relación coevolutiva de cultivo mantenida por una diversa gama de insectos con algunas especies de hongos. Se han documentado más de cuarenta especies de escarabajos de la ambrosía, así como avispas taladradoras, que cultivan hongos como fuente de alimentación. Igualmente, hormigas y termitas mantienen relaciones de este tipo con hongos (Rindos 1990: 113-114). Desde que la agricultura se practica intensivamente, el hombre mantiene una relación mutualista con las especies cultivadas; en cambio, guarda una relación competitiva con las especies vegetales que se infiltran en sus campos de cultivos, comúnmente conocidas como malas hierbas. La extracción y roza, que desde hace miles de años el hombre mantiene sobre estas especies, ayuda a la selección de unas pautas determinadas para tales tipos, que siguen prosperando en la actualidad. Las relaciones competitivas de coevolución positiva mutua quedan bien plasmadas en un ejemplo típico. A la vez que el guepardo cubre sus necesidades alimenticias a expensas de la gacela, la acción de la caza mediante la carrera crea un cuello de botella por el que prosperan gacelas genéticamente dispuestas a altas velocidades; en este caso, la víctima perfecciona su mecanismo de defensa.

De manera básica, en el apartado 3.2. se ha apuntado que las especies de un mismo género son generalmente muy semejantes en costumbres y constitución, y siempre en estructura. Como comulgan de la misma economía de la naturaleza, resulta evidente que la lucha entre ellas será mucho más vigorosa que la que mantendrán con los individuos de otros géneros (Darwin 1999: 130). Esta pauta incita a indagar, de manera más profunda, en la naturaleza de las relaciones que mantienen las especies; por ejemplo, en la tendencia seleccionada de la relación, o en la energía empleada en la misma, etc. Realmente, parece tratarse de cuestiones excesivamente abstractas y casi de un trato imposible a la hora de cuantificarlas. Sin embargo, desde la Biología nos llegan estudios que empiezan a abordar estas cuestiones.

Entre los biólogos de poblaciones, el coeficiente de competencia indica la intensidad del efecto de una especie sobre otra, con la que mantiene una determinada relación. Cuando entre las especies que mantienen una relación, uno o los dos coeficientes de competencia son negativos, tenemos situaciones de comensalismo o simbiosis. Han sido estudiadas estadísticamente las posibilidades de relaciones entre especies o grupos distintos. Evelyn Hutchinson anota que si el efecto de un individuo de una especie sobre el individuo de otra especie es mayor que el que produce sobre uno de sus congéneres, al mismo tiempo que un miembro de la segunda especie tiene menos efecto sobre uno de la primera del que tiene sobre su congénere, la especie primera desplazará a la segunda. Si los individuos de ambas especies mantienen un mayor efecto sobre los individuos de sus competidoras que sobre sus congéneres, la especie que triunfe es la que poseía una proporción inicial mayor en la población mixta en crecimiento. Por el contrario, si los individuos de cada especie mantienen un efecto mayor sobre sus iguales, en comparación al que mantienen sobre los individuos de la otra especie, se produce la coexistencia (Hutchinson 1981: 275-295). La aplicación de estos parámetros de estudio a los diferentes grupos humanos prehistóricos puede ofrecer una interesante información sobre el desarrollo y la sucesión de estas culturas.

ISSN: 1133-4525 ISSN-e: 2255-3924 


\subsection{El registro arqueológico}

Resulta harto difícil confirmar las reglas anteriores con base en el registro arqueológico. Primero, contamos por el momento con una cantidad escasa de datos que permita confirmar, de manera fehaciente, tales mecanismos regulares. Segundo, la misma naturaleza de los datos contiene, de manera intrínseca, cierto nivel de ambigüedad o imprecisión para despegar determinadas variables de análisis. Dicho de otra forma, la información no es fácilmente visible de manera directa, sino que requiere de unos estudios previos que permitan fijar algunas bases de clasificación del registro arqueológico; por ejemplo, la diferencia entre restos pertenecientes a especies domésticas o especies salvajes, que pueda arrojar alguna luz acerca de los tipos de relación -mutualismo, competición, etc.- que estos individuos mantuvieron. Suponemos que la aplicación de ciertas técnicas, como la Traceología, puede arrojar una interesante información sobre estas cuestiones, que son actualmente poco investigadas. Así, la aplicación de tales procedimientos puede permitir dilucidar acerca del tratamiento que los restos óseos tuvieron, y seguramente, este tratamiento difiere bastante según el tipo de relación que esa especie mantuviese con el hombre.

\subsubsection{El mutualismo}

La mayoría de las especies constatadas en los asentamientos humanos alude al aprovechamiento alimenticio. En cambio, hay otros casos que, aunque en parte han cubierto esta función, remiten a diversos usos; el Canis familiaris es un buen ejemplo. Esta especie se ha destinado a multitud de usos: como herramienta para el pastoreo, como guarda de bienes, etc. Ambos, hombre y perro, mantienen una dependencia basada en una especie de "pacto mutualista". Según estudios sobre Canis familiaris, los contextos y situaciones en el registro arqueológico son muy variados (Niveau y Ferrer 2004). Existen enterramientos de cánidos que muestran una gran inversión de tiempo y trabajo y, por ende, denotan la excepcionalidad de esta especie respecto a otras. También, el perro fue utilizado en los banquetes funerarios humanos. Pero, en contraposición, también hay evidencia del uso alimenticio de este animal. Aunque la diversidad de contextos documentados dificulta la labor de interpretación, no la hace imposible. Sencillamente, el manejo de este animal por el hombre es muy amplio, tanto cronológica como geográficamente. Ante estas circunstancias, se produce una mayor diversidad de concepciones y usos para con el perro, pues diremos que la variabilidad es directamente proporcional a la difusión geográfica. Por tanto, no debemos extrañarnos ante la diversidad que muestran los diferentes contextos arqueológicos donde han sido extraídos restos de cánidos. No obstante, la peculiaridad de enterramientos de cánidos y el significado que este animal ha tenido en diversos rituales humanos invitan a sospechar acerca del especial papel de este animal en algunas sociedades. Aunque la concepción humana hacia el perro no haya sido la misma en todas las zonas geográficas, la manipulación sobre este animal sí se ha dado en un sin fin de lugares. Por tanto, parece ser que el beneficio que el perro ha permitido al hombre sí ha sido similar en unas y otras zonas. En cambio, el pago de este beneficio o la recompensa humana a este pacto mutualista no se ha producido de idéntica forma en todos los puntos geográficos; sí han convergido, presumiblemente de forma análoga, casos de suma similitud. A este respecto, parece ser cierta la admisión del perro en el terreno divino, como portador de "almas" o símbolo de determinados dioses, a lo largo de gran parte del área mediterránea en la Protohistoria (Niveau y Ferrer 2004).

Abundantemente, se evidencia un tipo de relación mutualista, la que mantiene el hombre con la mayoría de especies domesticadas. Y es ésta, asegurar la crianza y, generalmente, la reproducción 
de estos tipos domésticos a cambio del pago en alimento, en la mayoría de los casos mediante la muerte del individuo. La seguridad que estas especies domésticas han obtenido del hombre, en cuanto a que les ha permitido reproducirse, consolidarse y difundirse por doquier, ha labrado genéticamente gran parte del comportamiento de estos individuos, que mantienen una estrategia de "selección de grupo" ${ }^{20}$, donde se actúa de manera que la especie, más que el individuo en sí, sea la beneficiada; en definitiva, un tipo de "cooperación intraespecífica". Este tipo concreto de relación mantiene el hombre con la mayoría de especies domésticas del registro arqueológico, aunque algunos ejemplos quedan complementados con otros «productos secundarios», tales como la tracción en bóvidos y équidos (Harrison y Moreno 1985).

El registro arqueológico del Bajo Guadalquivir muestra claramente lo que venimos apuntando. Desde aproximadamente el paso entre el VII y VI Milenio a.C., el tipo de relación "mutualista" que hemos explicado, o la domesticación de plantas y animales, dio sus primeros pasos (Mederos 1996). De forma general, y como las más difundidas, aparecen especies como Sus domesticus, Capra hircus, Ovis aries, Bos taurus, etc., lo que demuestra cómo y por qué dicha estrategia mutualista de domesticación de grupo ha sido universalmente seleccionada, ya que permite el arraigo de numerosas especies. Como decíamos, el registro arqueológico plasma de manera sistemática la abundancia de estos tipos. Valga a modo de ejemplo el caso de La Mesa de Setefilla, donde estas especies se documentan como las más numerosas a lo largo de toda la secuencia estratigráfica (Estévez 1983). En definitiva, una relación simbiótica o mutualista se produce cuando las dos especies implicadas se benefician correspondientemente y el índice de supervivencia es mayor, lo que posibilita elevar la biomasa de ambas.

El registro arqueológico del Bajo Guadalquivir permite el análisis de otro caso de simbiosis, concretamente, un sistema que se mantiene gracias a la «cooperación interespecífica» de sus elementos. Se trata de un sistema productivo similar al de la dehesa moderna ${ }^{21}$. Concretamente, a través de las fases del desarrollo de este sistema documentamos que los valores máximos de especies ruderales se encuentran asociados a altos índices de polen de Quercus. Esta correspondencia puede reflejar la existencia y el mantenimiento mismo de la dehesa, que se relaciona con actividades de clareo que -mediante una leve reducción leñosa del ecosistema que no afecta apenas a su equilibrio- (Barrientos 1998: 21) permiten una superficie de suelo abundante en hierbas, las cuales facilitan la exportación de polen (Tauber 1967; citado en Stevenson y Harrison 1992). De este modo, y alternándose según las distintas estaciones solares, plantas herbáceas y Quercetalia ilex (su fruto, la bellota) cubren toda la época del año como alimento para las especies animales integrantes del sistema, mayormente bóvidos, suidos y caprinos (ovejas y cabras) ${ }^{22}$. En definitiva, la relación simbiótica que conforman los integrantes de este sistema productivo, análogo a la dehesa moderna,

20. Frecuentemente, existen estrategias biológicas donde prima la «selección de grupo»y/o «selección de especie», por la cual los intereses de los individuos quedan sometidos al interés general de la población.

21. Desde su origen en época medieval, el término dehesa ha sufrido varios cambios en cuanto a su significado preciso. Para un estudio etimológico del término dehesa, y, el desarrollo que este concepto ha sufrido a lo largo de los siglos, véase (Martín y Fernández, e.p.).

Si bien el caso prehistórico, que data del IV Milenio B.C., no puede denominarse bajo el apelativo dehesa, no se trató de un sistema muy diferente, aunque diferiría de éste en cuestiones como la extensión del terreno, la protección y cercado, la "naturaleza jurídica", y, posiblemente, en otras dimensiones tales como el número de cabezas de ganado, la propiedad del terreno, etc. No obstante, creemos que la esencia de la dehesa -un sistema regulado y sostenible de diferentes tipos de Quercus sobre un suelo determinado, con un gran índice de especies herbáceas y, además, unos tipos animales tales como los suidos- estuvo presente en época prehistórica.

22. Se ha apuntado que cuando la densidad de encinas en un espacio dado no es muy alta, éstas aumentan la producción cuantitativa de bellotas (Grove y Rackham 2001; Martín y otros 1998). Al no ser necesario, por tanto, un alto índice en el número de árboles, es posible una mayor extensión de suelo para las especies herbáceas, que sustituyen a la bellota como alimento en su época de "vacas flacas" (Martín y Fernández, e.p.). Por otro lado, se recuerda (Martín y Fernández,

ISSN: 1133-4525 ISSN-e: 2255-3924

SPAL 13 (2004)

http://dx.doi.org/10.12795/spal.2004.i13.01 
permite que éste prospere y perdure durante una larga época. En los sitios onubenses de la Laguna de las Madres y El Acebrón, se documenta el origen de un sistema económico similar desde el IV Milenio BC, y se prolonga más de 5000 años (Stevenson y Harrison 1992). El éxito de este sistema viene dado pues de la mano de la relación simbiótica, que mantienen básicamente Quercus, ruderales -como Artemisia, Plantago, Cruciferae y Rumex-, caprinos, suidos, bóvidos y humanos, y que permite a este último explotar con un alto rendimiento el ecosistema dado mediante una reducida manipulación del mismo y con un bajo coste de inversión en el control de las especies restantes, frente a la otra posibilidad asequible de explotación del entorno, la de pastoreo y barbecho.

\subsubsection{Relaciones competitivas}

A modo de ejemplo, el yacimiento del Cerro de la Albina (La Puebla del Río, Sevilla) ilustra, entre otros muchos, el tipo general de relación competitiva, que suele desarrollarse en muchos casos mediante estrategias cinegéticas. En el caso concreto de este yacimiento, se evidencian restos de especies terrestres y acuáticas, que fueron cazadas por el hombre para la obtención de recursos alimenticios. Esta actividad depredadora del hombre se constata con los restos hallados de un zorro, de dos ciervos, de un jabalí, e igualmente hay evidencias de actividades de obtención de recursos de malacofauna terrestre y marítima ${ }^{23}$. El resto de especies documentadas en el yacimiento no permiten ser diferenciadas entre domésticas o salvajes. La presencia de malacofauna es abundante, destacando notablemente el número de restos localizados de especies terrestres sobre marinas. Han sido documentadas tres especies de malacofauna terrestre, que clasificamos en orden de mayor a menor cantidad de restos encontrados: Helix aspersa, Otala lactea y Rumina decollata. La malacofauna marina queda representada en una mínima proporción, donde destaca Solen marginatus, comúnmente conocida como navaja.

Si en el párrafo anterior hemos hecho referencia a un tipo de relación competitiva entre especies, concretamente la depredación, vemos oportuno citar otro claro ejemplo también visible en el registro arqueológico. Se trata de un tipo de competición entre individuos de la misma especie ${ }^{24}$. La competición entre individuos de una misma especie se muestra de manera clara en el caso de la selección sexual. Generalmente, en la gran mayoría de especies que poseen una reproducción sexual, el macho busca a la hembra. Esto acarrea una competición entre los individuos de sexo masculino para el disfrute de la hembra y, por ende, para plasmar la descendencia. Sabemos que la reproducción sexual dispone de mecanismos, muchos de ellos fuertemente retroalimentados, que gozan de gran importancia en cuanto al desarrollo somático de los individuos. En definitiva, cualquier cambio fisiológico que contribuye a captar la atención del sexo opuesto y, a la sazón, a elevar la reproducción diferencial, será promovido por la selección sexual. A este respecto, Darwin escribió:

e.p.) que los árboles permiten paliar las temperaturas extremas típicas de los paisajes de hierbas, a las que son altamente sensibles los cerdos (Laguna 1998).

23. Estos datos han sido obtenidos del estudio de paleofauna realizado para este yacimiento; parte de ellos aún no han sido publicados. Hacemos referencia al trabajo, aún inédito, del cual hemos recogido algunos datos: Bernáldez, E. y Bernáldez, M. "Aportación a la historia natural y social de La Puebla del Río (Sevilla) desde la basura del siglo VII a.C. Estudio paleobiológico y tafonómico del yacimiento arqueológico del Cerro de la Albina”, (inédito).

24. Aunque la obra de Darwin, que muestra la Teoría de la Evolución, ya diferenció entre «selección de grupo»y "selección de individuo», ésta última presume recientemente de más consideración entre los neodarwinistas. Desde que Richard Dawkins (1976) llevase la selección a nivel de genes, los estudios evolucionistas han ido desechando en cierta medida la selección de especie; de tal manera que gran parte de las publicaciones científicas evolucionistas recientes toman la selección natural a nivel de individuos o genes. 
"Por lo que a mí respecta, pues, afirmo que de todas las causas que promovieron diferencias exteriores entre las razas humanas, y hasta cierto punto entre éstas y los animales inferiores, la más eficiente fue la selección sexual» (Darwin 1994: 509).

En este punto, es importante apuntar la existencia de los «caracteres sexuales secundarios», aquellos que no están relacionados directamente con la reproducción, pero que intrínsecamente poseen importantes mecanismos bajo el motor de la selección sexual. Un buen ejemplo de estos aspectos lo encontramos en el proceso reproductivo de Cervus elaphus. El macho debe de proteger el harem de hembras mediante la berrea, y esta función se define y materializa en la cornamenta. Cuando los machos de cualquier especie poseen caracteres somáticos distintivos, o "armas", que no tiene la hembra, no hay duda de que sirven para las luchas con otros machos, y, esto ha sido producido bajo el modelado de dicha selección sexual (Darwin 1994: 428).

En definitiva, los mecanismos subordinados a la selección sexual impulsan el ritmo de cambio en la modificación de caracteres físicos y, también, de comportamientos y, a la sazón, permite mayor nivel de complejidad frente a otras especies, a la vez que fomenta las variedades y particularidades dentro de una misma especie. Algo similar a la función bélica y sexual de los cuernos de los ciervos ocurre en la imagen del guerrero humano de la sociedad del Bronce Final en tierras tartésicas, que se apoya en el mismo atributo: los cuernos, pero en este caso de toros. Las estelas del Suroeste que muestran individuos masculinos reflejan frecuentemente largos y estilizados cuernos además de la típica panoplia militar. Para el caso femenino, en ningún caso se acompaña de cuernos la cabeza del individuo representado ${ }^{25}$. Desde los postulados teóricos de la Arqueología Evolutiva no es tan importante dilucidar acerca de las primeras evidencias de cuernos en el registro arqueológico, sino más bien hurgar en los mecanismos que hacen que una determinada conducta, en este caso la plasmación sistemática de cuernos para el guerrero, quede fijada culturalmente, pues presumiblemente posibilita más reproducción diferencial que la conducta mantenida anteriormente. Así, en una sociedad ganadera, como es la del final de la Edad del Bronce meridional peninsular, el origen de cascos adornados de cornamentas quizás pudo estar en relación con el control de redes de ganado a cargo de individuos pudientes. La selección sexual hace perdurar las conductas que denotan la posición económica del individuo de cara al éxito de la atención de las mujeres en la elección de pareja. En una sociedad que se hace guerrera, como denota el registro arqueológico del Bronce Final tartésico, estos artilugios se fortalecen, pues el símbolo de los cuernos significa el valor militar y la fortaleza física del individuo que aseguran el mantenimiento de la hembra y de la prole. Como expone la tradición arqueológica peninsular, los sujetos de gran cornamenta representados en dichas estelas mantendrían un papel muy destacado sobre el resto de la sociedad, muy probablemente como guerreros y líderes del grupo ${ }^{26}$ (quienes encarnan sobremanera estos atributos y, por lo tanto, gozan crecidamente de las atenciones de las hembras). Además, como hemos citado anteriormente, la elección de pareja se manifiesta como uno de los mecanismos más significativos que posibilita diferencias externas entre las distintas culturas humanas. Esto explica por qué en el caso de las poblaciones orientales que llegan al sur peninsular de la mano de la colonización fenicia,

25. Acerca de mecanismos que operan bajo el motor de la selección sexual aún visibles en el registro arqueológico peninsular de la prehistoria reciente, véase Escacena y García Rivero (e.p.).

26. Al respecto de la selección sexual, se ha propuesto que la captura de recursos cinegéticos en las sociedades prehistóricas ha sido siempre papel de los hombres - en contraposición a las actividades de recolecta y forrajeo, a las que el hombre contribuye en un mínimo porcentaje-, pues esa actividad permite el despliegue de ciertas conductas viriles, capaces de captar las atenciones del resto del grupo y de las hembras. Además, las actividades de caza pudieron jugar un importante papel en la distribución de las tareas de trabajo en aquellas sociedades, permitiendo una mayor ascendencia política, económica y social de aquellos individuos "machos" (Hawkes y Bird 2002: 59).

ISSN: 1133-4525 ISSN-e: 2255-3924

SPAL 13 (2004)

http://dx.doi.org/10.12795/spal.2004.113.01 
los mecanismos de la selección sexual no obraron de idéntica forma, pues el uso de cornamentas se reserva a las divinidades. En cambio, existen otros elementos, que denotan una buena posición social y económica, que desempañan aquel papel, tales como perfumes y alabastrones, escarabeos, vajillas lujosas y otros materiales caros importados desde el Próximo Oriente.

Por último, queda encontrar en el registro arqueológico el tipo de dependencia que hemos denominado "relación competitiva de coevolución positiva mutua". En la documentación faunística del suroeste ibérico están altamente representadas algunas especies como Cervus elaphus y Oryctolagus cuniculus. Aparte de que estos tipos tienen una gran potencialidad de aptitud ante diferentes entornos medioambientales, con lo que son más comunes y están más extendidos, también pueden estar representados en mayor número en los yacimientos arqueológicos debido a otros factores. El trato que mantiene el hombre con estas especies puede tratarse de una relación competitiva de coevolución positiva mutua. Estos dos taxones tienen gran tendencia a acercarse a los poblados humanos. Los ciervos buscan las gramíneas, presentes en gran cantidad en los campos de cultivos humanos. Igualmente, los conejos suelen entrar en dichas plantaciones, pues se tratan de apetecibles manjares (Bernáldez y Bernáldez 2000: 147). El conejo puede llegar a diezmar las cosechas domésticas humanas, pero los perjuicios ocasionados se compensan de buena manera mediante la caza de algunos de ellos ${ }^{27}$. Además, este lazo coevolutivo podría reforzarse ante un enemigo común: el zorro. Posiblemente resulte un hábitat más seguro para el conejo los alrededores de un poblado humano, donde el zorro no sería bien recibido conocido el perjuicio que provoca en los rebaños domésticos. Dadas estas circunstancias el hombre selecciona la caza de estos dos tipos anteriores -el conejo y el ciervo-, pues resultan de una gran rentabilidad proteínica en relación al coste energético invertido en la caza. Prueba de lo que venimos apuntando la tenemos en el yacimiento de Papa Uvas (Aljaraque, Huelva) y en amplias y muy diversas zonas de Andalucía occidental (Morales 1986: 348). Un buen ejemplo es el de la cueva de Santiago Chica de Cazalla (Sevilla) donde, en su fase correspondiente al Neolítico Reciente, se documentan unas veinticinco especies, entre algunas domésticas actualmente y otras salvajes. En cambio, para su etapa calcolítica, se reduce a las especies hoy en día domésticas, más sólo dos taxones silvestres en la actualidad: ciervos y conejos (Bernáldez y Bernáldez 2000: 148). La existencia exclusiva de estos dos tipos silvestres a partir de la Edad del Cobre no deja de resultar interesante, dada la idea de la relación competitiva de coevolución positiva mutua basada en los campos de cultivos humanos, que se intensifican en dicha época. Asimismo, entre las especies salvajes del yacimiento prehistórico de Cerro Juré destacan notablemente el ciervo y, en segundo lugar aunque más escasamente, el conejo (Nocete y otros 1998: 94).

También en la región de Extremadura estos dos tipos animales están bien documentados. Existen unos porcentajes sobre la fauna que existía en la etapa comprendida entre el Calcolítico y el periodo romano, y que se han basado en los yacimientos arqueológicos en los que se han practicado trabajos arqueo-zoológicos (Castaños 1998). Durante toda esta etapa, ciervos y conejos son los más bien representados en cuanto a los taxones silvestres.

En definitiva, el alto índice de estas dos especies en el registro faunístico puede ser fruto en gran parte de una relación competitiva de coevolución positiva mutua ${ }^{28}$.

27. Se ha apuntado que por su tamaño, número de individuos, rapidez reproductiva y crecimiento, el conejo es la «especie comodín» para los carnívoros de mediana talla (donde se incluye el hombre) cuando escasea la caza de otras especies (Bernáldez y Bernáldez 2000: 136).

28. Aunque posiblemente se trate de un hecho casual, resulta curiosa la gran plasmación que el conejo tiene en las esculturas ibéricas, como en el caso de Muela de Cástulo, Jaén (Ruiz y Molinos 1993: 108). 


\section{SUCESIÓN ECOLÓGICA}

Los parámetros de estudio con los que cuentan los biólogos, y concretamente los ecólogos, para indagar sobre el desarrollo de los ecosistemas resultan de gran interés para todo aquello que se pueda entender como un sistema (compuesto por múltiples elementos) y su desarrollo en el tiempo. La aplicación de este marco teórico que cuantifica y deduce "regularidades" de cualquier proceso de desarrollo puede ser una importante herramienta para el estudio de las culturas antiguas y, además, para el análisis de subsistemas humanos, tales como sistemas económicos y sociales. Es por lo que dedicamos un apartado, aunque sucinto, a resumir los puntos más básicos y significativos de esta herramienta. No obstante, la aplicación práctica de estos parámetros teóricos al campo de la arqueología requiere de trabajos particulares, que profundicen sólo en estos temas. El tratamiento empírico de tales aspectos excede los límites y objetivos de nuestro trabajo, a la vez que lo ampliaría en demasía. Por ello, como hemos dicho anteriormente, sólo expondremos la sucesión ecológica a través de breves y sencillas nociones teóricas, pues se trata de un nuevo enfoque (y esto sí es uno de los objetivos en este estudio) para el tratamiento de las culturas prehistóricas.

En un sistema cualquiera, la sucesión ecológica es el paso de un estado dado a otro, de nuevas características en relación al anterior. El término sucesión ha sido empleado por distintas áreas de conocimiento, las cuales han usado diferentes acepciones de dicho concepto según la percepción de la vida de cada uno de tales campos del saber. En este trabajo, recogemos la versión que acepta la Ecología. Brevemente, por ejemplo, los ecólogos interesados en la estructura han utilizado el concepto de sucesión como un desarrollo de la biomasa de los ecosistemas. Por otro lado, los más dinámicos han primado la maximización de la producción o del flujo de la energía de un ecosistema como el máximo indicador de sucesión (Margalef 1974: 770). De una forma u otra, lo que sí parece aceptado es que cualquier formación natural mantiene una sucesión de estados en los cuales la tendencia general es la disminución de la energía para mantener la masa unidad del sistema o, lo que es lo mismo, un aumento de esa masa unidad del sistema bajo la misma energía (Margalef 1974: 779). En el estudio sistemático de la sucesión hay dos parámetros que cuentan con gran importancia: ritmos y fluctuaciones. La sistematización de estos acontecimientos posibilita una cierta regularidad en un determinado proceso de sucesión y, por ende, minimiza en la medida de lo posible los agentes arbitrarios. Pensamos que cualquier formación natural o, incluso, cualquier sistema arquitectónico, económico o social humano pueden ser analizados desde esta perspectiva, ya que permite encuadrar a la especie humana dentro de un nicho ecológico más completo en cuanto al número de variables influyentes en un sistema dado.

Generalmente, en el desarrollo de cualquier sistema se van sucediendo etapas cada vez más complejas $^{29}$. De ahí que algunas ciencias de la vida, como la Biología o la Ecología, hayan diferenciado de manera básica entre dos tipos de ecosistemas: jóvenes y maduros (conceptos éstos válidos sólo bajo la metodología comparativa). En los ecosistemas jóvenes, la disponibilidad de nutrientes es más asequible, pues hay menor número de especies, que a la vez están menos especializadas para aprovechar de manera óptima el flujo de energía existente en el sistema ${ }^{30}$. Habiendo tanta energía

29. Aunque esto sea lo más comúnmente dado, existen etapas de larga estabilidad y otras que dirigen el desarrollo de los sistemas a estados menos complejos, como es el caso de la "regresión".

Normalmente, las sucesiones que poseen unos ritmos y fluctuaciones más regulares son capaces de ser sistematizadas hasta llegar a plasmarse mediante fórmulas matemáticas, que maximizan o minimizan algún valor dado hasta poder llegar a predecir estadios venideros; las sucesiones donde existen mayor número de variables aleatorias son, normalmente, menos predecibles, al menos que tales agentes arbitrarios puedan considerarse como una variable regular de tales ecuaciones.

30. Desde las leyes termodinámicas, sabemos que la energía no se pierde, sino que cambia de estado o, dicho de otro modo, de calidad. En un sistema joven, las especies existentes no son capaces de procesar el flujo de energía en muchos 
disponible, sin ser necesaria una alta especialización para su procesado, las especies de un sistema joven invierten en procrear gran número de individuos que ocupen el máximo territorio posible, lo que se ha denominado "sistema reproductivo r". En cambio, los sistemas maduros tienden a procesar la energía en muchos de sus estados o calidades, lo que permite que los nutrientes tengan mayor perduración en el tiempo y que se produzca menos biodegradación, o lo que es lo mismo, que los nutrientes se degraden sin ser aprovechados por las especies que ocupan el sistema. Esta captura óptima de la energía se produce porque, en los sistemas maduros, existe una gran diversidad de especies, que al mismo tiempo están muy especializadas en el procesado de un estado de la energía. Esta especialización se produce bajo un "sistema reproductivo K" que apenas invierte en el número de vástagos pero sí en su cuidado, pues el sistema está ahora densamente ocupado de especies. Como hemos apuntado anteriormente, la diversidad en los sistemas maduros permite la concentración de nutrientes ${ }^{31}$. No obstante, un entorno de estas características no está exento de cambios que -como cambios climáticos drásticos, diferencias entre las relaciones de las especies, o incluso por la llegada de extraños taxones foráneos- pueden empujarlo incluso a una disminución de la concentración de nutrientes y, por lo tanto, a un estado menos complejo.

Quizá la aplicación de estos parámetros a determinados periodos prehistóricos mereciese una cierta consideración. Por ejemplo, la transición del Calcolítico al Bronce en todo el mediodía ibérico. Durante la Edad del Cobre se produce un gran ascenso demográfico, que se basa fundamentalmente en un sistema agrícola intensivo, donde un "sistema reproductivo $r$ " parece haber tenido lugar. Este sistema económico fundamentalmente agrícola posibilita, y a la vez necesita, de una inversión en el número de la prole como mano de obra disponible para tales actividades de laboreo, ya fuese a nivel familiar o del grupo en general -mediante instituciones dirigidas por un sector social concreto-. Así parece indicarlo la cultura material de estos pueblos, fundamentalmente con grandes platos y otros recipientes de uso colectivo. Como "sistema económico y social joven", la disponibilidad de nutrientes era más asequible, pero sin embargo esta sociedad estaba menos especializada en cuanto a un aprovechamiento eficaz de la energía se refiere, pues su economía se basaba mayormente en la agricultura. Sin embargo, en la etapa final del Calcolítico se constata una serie hechos que reflejan un notable cambio en los modos económicos y sociales. Se trata del surgimiento o desarrollo de diversos sectores, como la metalurgia, la "revolución de los productos secundarios" y la aparición de diversos materiales peculiares. Es interesante, por ejemplo, el acceso restringido socialmente a ciertas vajillas, como por ejemplo a la cerámica campaniforme; y, posteriormente, el uso individualizado de las vajillas cerámicas de la Edad del Bronce. En definitiva, se manifiesta una cierta madurez en dicho ecosistema económico y social que, mediante el origen de nuevos puestos productores o nuevas ocupaciones laborales procesan mayor número de estados energéticos. La notable reducción de la población que se evidencia en los inicios de la Edad del Bronce está en relación con estos procesos anotados. Ahora bien, discernir entre la causa o las causas que provocaron estos cambios queda fuera de los límites de este trabajo. De forma básica, podría tratarse tanto de factores "alóctonos"-que proceden desde fuera del sistema-como de una conjunción de factores "autóctonos", lo que a priori parece factible dados los notables cambios económicos, sociales e, incluso, políticos que parecen haber tenido lugar.

de sus estados o calidades, pues aquellas especies, al estar en un ecosistema poco ocupado, invierten mayormente en la cantidad de procreación, y no en la especialización de sus organismos.

31. Normalmente, los sistemas maduros organizados explotan a los sistemas jóvenes, con menos complejidad en su organización. 


\subsection{Otras cuestiones sobre la sucesión relacionadas con el Bajo Guadalquivir}

No es de extrañar que a lo largo de una secuencia cronológica prolongada en un espacio geográfico dado, se sucedan tipos o especies muy similares entre sí. La teoría de la descendencia con modificación por selección natural contempla la ley de sucesión de los mismos tipos en las mismas áreas geográficas (Darwin 1999: 455). Esto es, que en cualquier zona geográfica tienden a sucederse taxones muy semejantes a los que existieron en un pasado. Esta ley de sucesión comprende periodos muy dilatados en el tiempo, incluso procesos desarrollados desde época Terciaria. A lo largo de este trabajo hemos anotado varias de las especies existentes en la Prehistoria Reciente del mediodía ibérico. El registro arqueológico de fauna y de polen documenta mayormente especies aún vivientes en la actualidad. En definitiva, el tiempo que ha transcurrido desde entonces no ha hecho cambiar en demasía las características básicas de dicho territorio, más aún cuando apenas se han producido cambios sustanciales en dimensiones como la geomorfología y el clima ${ }^{32}$. La ley anteriormente citada se basa en la premisa de que cualquier género desciende de una sola especie. El rastreo de la descendencia con modificación y sucesión de especies ha sido estudiado desde la biología por métodos filogenéticos ${ }^{33}$. La aplicación de esta metodología en la clasificación del registro arqueológico puede ofrecer una información importante, incluso novedosa, en la Arqueología de los próximos años.

Otra cuestión que influye en la sucesión general de cualquier espacio geográfico dado es la incorporación de nuevas especies procedentes de otras áreas territoriales. Los elementos foráneos que llegan a un ecosistema tienen dos posibilidades: prosperar o extinguirse. En la mayoría de los casos, la especie que llega al nuevo nicho tiene difícil reproducción y adaptación al medio, aunque en contadas ocasiones existe cierta aptitud para con el nuevo ecosistema. Esto ocurre cuando, de alguna manera, hay un puesto vacío en la lucha por la supervivencia de dicho sitio. En la mayoría de los casos, cuando una nueva especie se instala en un nicho ambiental causa importantes efectos (como ya vimos en el apartado 2.1.; hechos que han sido estudiados, como en el caso de «la hipótesis de la Reina Roja» (Van Valen 1973), anotado en el pie de página número 6). La llegada de la población oriental causó grandes cambios en el ecosistema tartésico. Quedan documentadas en el registro arqueológico varias especies, tanto animales - asno, gallina y una especie de oveja- como vegetales -olivo ${ }^{34}$, vid $^{35}$ y granada- (Stevenson y Harrison 1992: 236). En el yacimiento de La Alcazaba de Lebrija tenemos documentada la introducción del gallo alrededor del 500 a.C. (Bernáldez y Bernáldez 2000: 139). Esta especie está documentada también en otros yacimientos de la Edad del Hierro II en tierras extremeñas: Medellín 91 y Cerro II de Fuente de Cantos (Badajoz), y Villasviejas del Tamuja (Botija, Cáceres) (Castaños 1998: 68). Igualmente, para este periodo

32. Por ejemplo, estudios de la geografía antigua del Bajo Guadalquivir apuntan a que, a excepción de la franja litoral, los rasgos de la paleogeografía tartésica, en cuanto a geomorfología y clima, fueron similares a los de la actualidad, si bien es cierto se ha producido la introducción de nuevas especies forestales (Díaz del Olmo 1989: 20).

33. El estudio filogenético es igualmente denominado metodología cladística. Los trabajos pioneros en esta línea datan de los años 60 (Hennig 1965 y 1966; Wagner 1961) y argumentan sobre la importancia en la diferenciación entre caracteres primitivos (plesiomorfias) y caracteres derivados (apomorfias), los cuales hacen posible vincular a unas especies y otras con sus ancestros comunes.

34. Se ha anotado la posibilidad de uso de la técnica del injerto de olivos domésticos en viejos acebuches silvestres, cosa que elimina la gran inversión a emplear en la etapa de crecimiento de la planta y posibilita la recogida de frutos a corto plazo para una gente con una esperanza de vida reducida (Escacena 2000b: 125).

35. Aunque algunos autores apuntan la posibilidad de cultivo de la vid en la franja meridional de la península ya en el III Milenio a.C., los datos paleobotánicos no permiten saber con seguridad si se trata de una especie doméstica. No obstante, en la Edad del Bronce pudieron producirse algunas rupturas en el proceso de transmisión cultural vertical de los conocimientos agrícolas (dada la reducción del número de población humana y, presumiblemente, la sustitución de la agricultura como eje principal del sistema económico por otras tareas de producción), lo que pudo desembocar en la pérdida de las habilidades para el cultivo de algunas especies.

ISSN: 1133-4525 ISSN-e: 2255-3924 
queda documentada la presencia del asno en esta región: La Ermita de Belén de Zafra (Badajoz), Capote (Higuera la Real, Badajoz) y Villasviejas del Tamuja (Botija, Cáceres) (Castaños 1998: 68). La afluencia desde Oriente de todas estas especies causó importantes efectos en el sur peninsular, llegando a cambiar las bases de subsistencia de estas comunidades; además, la introducción de nuevos conocimientos tecnológicos y herramientas pudieron potenciar nuevos menesteres laborales, tales como las actividades de roza (Stevenson y Harrison 1992: 236). En definitiva, son bien conocidos los cambios económicos-culturales que el arribo de estas especies motivaron en la población autóctona, y, que medraron en los aspectos más variados.

Entendemos que estas especies orientales gozaron de buena reproducción y prosperidad en tierras tartésicas debido a la existencia de puestos vacíos en dicho entorno. Las comunidades precoloniales consumieron mayormente recursos de tipo ganadero y pastoril. Este sistema económico no permite una explotación máxima del territorio. En estas circunstancias, la población oriental que introducía un sistema económico basado, entre otras cosas, en una fuerte agricultura intensiva, que permite el sustento de una población mayor, fue rápidamente seleccionada ${ }^{36}$. Este reciente sistema económico se complementaba con otras perspectivas de producción como la ganadería y el sector de intercambios o comercio, tanto entre las distintas poblaciones de la zona como con otros pueblos diseminados a lo largo del Mediterráneo antiguo.

\section{BIBLIOGRAFÍA:}

ARSUAGA, J.L. y MARTÍNEZ, I. (2000): La Especie Elegida: la larga marcha de la evolución humana. Madrid, Temas de Hoy.

ARTEAGA, O. y ROOS, A.M. (1992): "El Proyecto Geoarqueológico de las Marismas del Guadalquivir. Perspectivas arqueológicas de la campaña de 1992", Anuario Arqueológico de Andalucía 1992/ II: 329-339. Sevilla, Consejería de Cultura de la Junta de Andalucía.

ARTEAGA, O.; SCHULZ, H. y ROOS, A.M. (1995): "El Problema del 'Lacus Ligustinus'. Investigaciones Geoarqueológicas en torno a las Marismas del Bajo Guadalquivir", Tartessos 25 Años Después (1968-1993): 99-135. Jerez de la Frontera, Ed. Buc 14.

ATKINS, P.W. (1992): La segunda ley. Barcelona, Prensa Científica.

AYALA, F.J. (1994): La teoría de la evolución. De Darwin a los últimos avances de la genética. Madrid, Temas de hoy.

BARRIENTOS, G. (1998): "Introducción geográfica: Extremadura, una realidad diversa", en RODRÍGUEZ DÍAZ, A. (Coord.): Extremadura Protohistórica: Paleoambiente, Economía y Poblamiento: 15-28. Cáceres, Universidad de Extremadura.

BEJARANO, R. (1997): Vegetación y paisaje en la costa atlántica de Andalucía. Sevilla, Universidad de Sevilla.

BERNÁLDEZ, E. y BERNÁLDEZ, M. (2000): "La basura orgánica de Lebrija en otros tiempos. Estudio paleobiológico y taxonómico del yacimiento arqueológico de la Calle Alcazaba de Lebrija (Sevilla)", Boletín del Instituto Andaluz de Patrimonio Histórico 32: 134-150. Consejería de Cultura de la Junta de Andalucía.

BERNÁLDEZ, E. y BERNÁLDEZ, M. (inédito): "Aportación a la historia natural y social de La Puebla del Río (Sevilla) desde la basura del siglo VII a.C. Estudio paleobiológico y tafonómico del yacimiento arqueológico del Cerro de la Albina".

36. Sobre la comparación entre los sistemas productivos de las poblaciones tartésicas precoloniales y de época orientalizante, véase (Escacena 2000b). 
BLACKMORE, S. (2000): La Máquina de los Memes. Barcelona, Ed. Paidós.

CASTAÑOS, P.M. (1998): "Evolución de las faunas protohistóricas en Extremadura", en RODRÍGUEZ DÍAZ, A. (Coord.): Extremadura Protohistórica: Paleoambiente, Economía y Poblamiento: 63-72. Cáceres, Universidad de Extremadura.

CERLING, T. y otros (1997): "Global vegetation change through the Miocene/Pliocene boundary, Nature 389: 153-158.

CHILDE, V. G. (1992): Los Orígenes de la Civilización. Madrid, Breviarios.

COHEN, M.N. (1993): La crisis alimentaria de la prehistoria. La superpoblación y los orígenes de la agricultura. Madrid, Alianza Editorial.

COX, S.J.; SLUCKIN, T.J. y STEELE, J. (1999): "Group Size, Memory, and Interaction Rate in the Evolution of Cooperation", Current Anthropology 40: 369-377.

DARWIN, Ch.R. (1994). El origen del hombre y la selección en relación al sexo. Madrid, Edaf.

DARWIN, Ch.R. (1999): El Origen de las Especies. Madrid, Albor Libros.

DAWKINS, R. (1976): The Selfish Gene. New York, Oxford University Press. (En la versión en castellano de esta obra (1979): El Gen Egoísta. Las Bases Biológicas de Nuestra Conducta. Barcelona, Salvat.

DÍAZ DEL OLMO, F. (1989): "Paleografía tartésica", en AUBET, M.E.: Tartessos. Arqueología Protohistórica del Bajo Guadalquivir: 13-23. Sabadell, Ausa.

ESCACENA, J.L. (2000a): La arqueología protohistórica del Sur de la Península Ibérica. Historia de un río revuelto. Colección Arqueología Prehistórica 4. Madrid, Ed. Síntesis.

ESCACENA, J.L. (2000b): "Los negocios del campo, de la industria, del comercio y del mar", en ARANEGUI, C. (ed.), Argantonio, Rey de Tartessos: 116-135. Sevilla, Fundación El Monte.

ESCACENA, J.L. y GARCÍA RIVERO, D. (e.p.): "Sexualidad y Reproducción en la Prehistoria Reciente de Iberia. Cortejo Epistemológico desde la Arqueología Evolutiva", La Imagen del Sexo en la Antigüedad. Ciclos de Renovación de la Vida. Barcelona, Tusquets Editores.

ESTÉVEZ, J. (1983): "La fauna del corte 3: aproximación a la fauna del yacimiento de Setefilla", en M.E- Aubet y otros: La Mesa de Setefilla. Lora del Río (Sevilla). Campaña de 1979. (Excavaciones Arqueológicas en España 122): 158-168. Madrid, Ministerio de Cultura.

GRAU, E.; PÉREZ, G. y HERNÁNDEZ, A.M. (1998): "Paisaje y agricultura en la Protohistoria Extremeña", en RODRÍGUEZ DÍAZ, A. (Coord.): Extremadura Protohistórica: Paleoambiente, Economía y Poblamiento: 31-62. Cáceres, Universidad de Extremadura.

GROVE, A.T. y RACKHAM, O. (2001): The nature of Mediterranean Europe. An Ecological History. New Haven, Yale University Press.

HARRISON, R.J. y MORENO, G. (1985): "El policultivo ganadero o la revolución de los productos secundarios", Trabajos de Prehistoria 42: 51-82. Madrid, Centro de Estudios Históricos.

HAWKES, K. y BIRD, R.B. (2002): "Showing Off, Handicap Signaling, and the Evolution of Men's Work". Evolutionary Anthropology 11: 58-67.

HENNIG, W. (1965): "Phylogenetic Systematics", Annual Review of Entomology 10: 97-116.

HENNIG, W. (1966): Phylonetic systematics. Urbana, Univ. Illinois Press.

HOROWITZ, A. (1981): “Geología y Paleoambiente", en A. Blanco y B. Rothenberg: Exploración Arqueometalúrgica de Huelva: 183-202. Barcelona, Labor.

HUTCHINSON, G.E. (1981): Introducción a la ecología de poblaciones. Barcelona, Blume ecología. LAGUNA, E.(1998): El cerdo ibérico en el próximo milenio. Madrid, Mundi Prensa.

LÓPEZ, P. (1978): "Resultados polínicos del Holoceno en la Península Ibérica", Trabajos de Prehistoria 35: 9-44. Madrid, Centro de Estudios Históricos.

LÓPEZ, P. (1986): "Estudio palinológico del Holoceno Español a través del análisis de yacimientos arqueológicos", Trabajos de Prehistoria 43: 143-158. Madrid, Centro de Estudios Históricos.

MARGALEF, R. (1974): Ecología. Barcelona, Omega.

ISSN: 1133-4525 ISSN-e: 2255-3924

SPAL 13 (2004)

http://dx.doi.org/10.12795/spal.2004.113.01 
MARTÍN, A. y FERNÁNDEZ, R. (e.p.): "An historical perspective for the rangeland economy in dehesas", en Joffre, R. (Edit.): The Dehesas, Ed. Kluver.

MARTÍN, A. y otros (1998): "Producción de bellotas en montes y dehesas del suroeste español". Pastos XXVIII (2): 237-248.

MARTÍN, E.; RUSE, M. y HOLMES, E. (1996): A Dictionary of Biology. Oxford, Oxford University Press.

MASCHNER, H.D.G. (ed.) (1996): Darwinian archaeologies. New York, Plenum.

McMULLIN, E. (1983): "Values in Science", en ASQUITO, P.D. y NICKLES, T.: Philosophy of Science Association: 3-28. East Lansing, Mich.

MEDEROS, A. (1996): "La cronología absoluta de Andalucía occidental durante la Prehistoria reciente", Spal 5: 45-86.

MORALES, A. (1986): Informe faunístico del yacimiento. Corte C-4.3. Fondo $\mathrm{n}^{\mathrm{o}} 3$. Sector C, en MARTÍN DE LA CRUZ: "Papa Uvas II. Aljaraque, Huelva. Campañas de 1981 a 1983", E.A.E 149: 345-350. Madrid, Ministerio de Cultura.

NIVEAU, A.M. y FERRER, E. (2004): "Sacrificios de cánidos en la necrópolis púnica de Cádiz", III Congreso Español de Oriente Próximo Antiguo, Huelva Arqueológica 20: 63-88.

NOCETE, F. y otros (1998): "Estudio del material arqueológico de la primera campaña de excavación de C. Juré (Alosno, Huelva). Proyecto Odiel”, Anuario Arqueológico de Andalucía 1995/ II: 93-104. Sevilla, Consejería de Cultura de la Junta de Andalucía.

O'BRIEN, M.J. y LYMAN, L. (2000): Applying evolutionary archaeology. A systemcatic approach. New Cork, Plenum.

RINDOS, D. (1990): Los orígenes de la agricultura. Una perspectiva evolucionista. Barcelona, Bellaterra.

RUIZ, A.; MOLINOS, M. (1993): Los iberos. Análisis arqueológico de un proceso histórico. Barcelona. Crítica.

RUSE, M. (2001): El misterio de los misterios. ¿Es la evolución una construcción social? Barcelona, Tusquets Editores.

SCHULZ, H.D.; FELIS, T.; HAGEDORN, Ch.; VON LÜHRTE, R.; REINERS, C.; SANDER, H.; SCHNEIDER, R.; SCHUBERT, J. y SCHELZ, H. (1992): "La línea costera holocena en el curso bajo del Río Guadalquivir entre Sevilla y su desembocadura en el Atlántico. Informe preliminar sobre los trabajos de campo realizados en Octubre y Noviembre de 1992", Anuario Arqueológico de Andalucía 1992/ II: 323-327. Sevilla, Consejería de Cultura de la Junta de Andalucía.

SHENNAN, S. (2002): Genes, memes and human history. Darwinian archaeology and cultural evolution. London, Thames \& Hudson.

SIGMUND, K.; FEHR, E. y NOWAK, M.A. (2002): "La economía del juego limpio", Investigación y Ciencia 306: 23-27.

SMIL, V. (2001): Energías. Una guía ilustrada de la biosfera y de la civilización. Madrid, Crítica.

STEVENSON, A.C. y HARRISON, R.J. (1992): "Ancient Forests in Spain: A Model for Land-use and Dry Forest Management in South-west Spain from 4000 BC to 1900 AD", Proceedings of the Prehistoric Society 58: 227-247.

TANSLEY, A.G. (1935): "The use and abuse of vegetational concepts and terms", Ecology 16 (3): 284-307.

TAUBER, H. (1967): "Investigations of the mode of pollen transfer in forested areas", Reviews of Palaeobotany and Palynology 3: 277-287.

VAN VALEN, L. (1973): "A new evolutionary law", Evolutionary Theory 1: 1-30.

WAGNER, W.H., Jr. (1961): "Problems in the Classification of Ferns", Recent Advances in Botany, Int. Bot. Cong., $9^{\text {th }}$, Symp., Montreal, 1959, vol. 1, University of Toronto Press, 1961: 841-844. 